Article published in Nucl. Instr. Meth. B 262 (2007) 281

\title{
International Atomic Energy Agency intercomparison of Ion Beam
}

\section{Analysis software}

N.P. Barradas ${ }^{\text {a,b, }}{ }^{*}$, K. Arstila ${ }^{\text {c }}$, G. Battistig ${ }^{\text {d }}$, M. Bianconi ${ }^{\text {e }}$, N. Dytlewski ${ }^{\text {f }}$, C. Jeynes ${ }^{\text {g, }}$, E. Kótai ${ }^{\text {h}}$, G. Lulli ${ }^{\text {e }}$, M. Mayer ${ }^{i}$,E. Rauhala ${ }^{j}$, E. Szilágyi ${ }^{\text {h }}$, M. Thompson ${ }^{k}$

a Instituto Tecnológico e Nuclear , Estrada Nacional No. 10, Apartado 21, 2686-953

Sacavém, Portugal

b Centro de Física Nuclear da Universidade de Lisboa, Av. Prof. Gama Pinto 2, 1649-003 Lisboa, Portugal

c K.U.Leuven, Instituut voor Kern- en Stralingsfysica, Celestijnenlaan 200D, B-3001 Belgium

d MFA Research Institute for Technical Physics and Materials Science, P.O.Box 49, H-1525 Budapest, Hungary

e CNR-IMM-Sezione di Bologna, Via P.Gobetti, 101, I-40129 Bologna, Italy

$f$ International Atomic Energy Agency, Wagramer Strasse 5, P.O. Box 100, A-1400 Vienna, Austria

$g$ Surrey Ion Beam Centre, University of Surrey, Guildford, Surrey GU2 7XH, England

h KFKI Research Institute for Particle and Nuclear Physics, P.O. Box 49, H-1525 Budapest, Hungary

Max-Planck-Institut für Plasmaphysik, EURATOM Association, Boltzmannstrasse 2, D85748 Garching, Germany 
j Accelerator Laboratory, Dept. of Physics, University of Helsinki, P.O. Box 43, FIN-00014

Helsinki, Finland

${ }^{k}$ Dept. of MS\&E/Bard Hall 328, Cornell University, Ithaca, NY 14853, USA

* Corresponding author. Tel: +351 219946150; fax: +351 219941039. E-mail address: nunoni@itn.pt

\begin{abstract}
Ion Beam Analysis (IBA) includes a group of techniques for the determination of elemental concentration depth profiles of thin film materials. Often the final results rely on simulations, fits, and calculations, made by dedicated codes written for specific techniques. Here we evaluate numerical codes dedicated to the analysis of Rutherford Backscattering Spectrometry (RBS), non-Rutherford Elastic Backscattering Spectrometry, Elastic Recoil Detection Analysis, and non-resonant Nuclear Reaction Analysis data. Several software packages have been presented and made available to the community. New codes regularly appear, and old codes continue to be used and occasionally updated and expanded. However, those codes have to date not been validated, or even compared to each other. Consequently, IBA practitioners use codes whose validity, correctness and accuracy have never been validated beyond the authors' efforts. In this work, we present the results of an IBA software intercomparison exercise, where seven different packages participated. These were DEPTH, GISA, DataFurnace (NDF), RBX, RUMP, SIMNRA (all analytical codes) and MCERD (a Monte Carlo code). In a first step, a series of simulations were defined, testing different capabilities of the codes, for fixed conditions. In a second step, a set of real experimental data were analysed. The main conclusion is that the codes perform well within the limits of their design, and that the largest differences in the results obtained are due to differences in the
\end{abstract}


fundamental databases used (stopping power and scattering cross section). In particular, spectra can be calculated including Rutherford cross-sections with screening, energy resolution convolutions including energy straggling, and pileup effects, with agreement between the codes available at the $0.1 \%$ level. This same agreement is also available for the non-RBS techniques. This agreement is not limited to calculation of spectra from particular structures with predetermined parameters, but also extends to extracting information from real data. In particular, we have shown data from an $\mathrm{Sb}$ implanted sample where the Sb fluence was certified with an uncertainty of $0.6 \%$. For this sample, and using SRIM03 stopping powers for $1.5 \mathrm{MeV} 4 \mathrm{He}$ in $\mathrm{Si}$, the codes were able to extract the $\mathrm{Sb}$ fluence with an average $0.18 \%$ deviation from the certified value and a $0.11 \%$ agreement between the codes. Thus IBA is a suitable technique for accurate analysis where traceability is critical. These results confirm that available IBA software packages are, within their design limitations, consistent and reliable. The protocol established may be readily applied to validate future IBA software as well.

PACS: 01.30.Rr; 07.05.Kf; 82.80.Yc; 34.50.Bw

Keywords: Ion beam analysis; computer software; data analysis; simulation; silicon; stopping power 


\section{Introduction}

Low-energy particle accelerators have contributed a major part of our current knowledge of nuclear physics. The scientific outputs and technology developed in the pursuit of a better understanding of the atomic nucleus have evolved into mature accelerator applications supporting amongst other things, materials modification and materials analysis. Ion Beam Analysis (IBA), with its historical roots in ion beam interactions with atoms and nuclei, is the mainstay of the utilization of many low-energy ion beam accelerators. A recent survey conducted by the International Atomic Energy Agency (IAEA) ${ }^{1}$ showed that there are more than 200 particle accelerators in 40 countries that utilise IBA techniques to various extents. The primary IBA techniques used are PIXE (Particle Induced X-Ray Emission), PIGE (Particle Induced Gamma-ray Emission), RBS (Rutherford Backscattering Spectrometry), Elastic (non-Rutherford) backscattering spectrometry (EBS), NRA (Nuclear Reaction Analysis) and ERDA (Elastic Recoil Detection Analysis).

Practitioners of IBA and researchers who utilise IBA techniques as part of their work are dependent on the availability of suitable analytical software and the accuracy of the outputs. Many software packages have been developed over time to address ongoing endusers needs and expectations. Understandably, they are of little commercial interest since they demand high amounts of intellectual input, and have limited profit potential. Computer programs to analyse data from the particle-particle IBA techniques of RBS, NRA, and ERDA date back to the 1970s. The needs of ion beam production, modification, and characterisation techniques from outside the ion beam community began to arise with the growing semiconductor technology. These IBA techniques for quantitative depth profiling in the micron range and determination of low-concentration elemental impurities were quickly recognized and widely applied. As these analytical tools became more versatile, also the 
samples, spectra and data analysis problems became more complicated. By the end of the 1990s, the codes had developed in various directions; codes exist which can handle very general data analysis problems and various IBA techniques, some are highly automatic, others treat specified problems with great exactness.

The simulation modelling used in all IBA software assumes that the underlying physics, mathematics and nuclear and atomic data are valid, and adequately describe the physical processes involved. Starting from a known sample structure, the corresponding experimental energy spectrum, be it either particle or electromagnetic, created from ion beam interactions can be theoretically simulated from a few basic data, and the known formalism of the reaction spectrometry. Comparing the experimental and theoretical spectra, after a few user-conducted iterations where the assumed composition of the sample is iteratively modified, a close similarity of the spectra is accomplished. The sample structure leading to the theoretical spectrum is then taken to correspond to the material's sample structure. Erroneous results or misinterpretations of the material's structure can result from incorrect science, ambiguous data, or inadequate documentation and guidance for people to extract the correct information. The analytical software in wide-spread use today has underlying physics and computational strategies that in most applications have been demonstrated to be reliable and robust. This conclusion arises from the long track record of good agreement with other results obtained from independent and complementary techniques. With evolving technologies, IBA is being called upon to analyse increasingly complex materials, creating new challenges for IBA software. Of emerging importance is the necessity for IBA users to have sufficient confidence and evidence of the ability of the software codes to produce reliable and correct results, if used properly.

The IAEA organised in 2002 a technical meeting on the "Status of Software for Ion Beam Analysis in Materials Development" 2, where 12 different particle-particle analysis 
software packages were identified, each using various nuclear models, nuclear data, physics and mathematical algorithms. A description of these particle-particle software packages, a history of their development, and a review of their current status has been published ${ }^{3}$. The present paper describes the results of an IAEA exercise undertaken with the objectives to compare and ascertain the reliability and correctness of the outputs of seven different particleparticle analytical software codes. The usability (ease of use) and documentation of these codes were not assessed.

Although falling in the general IBA rubric, PIXE and PIGE will not be discussed in this paper. The IAEA has previously reviewed the status of gamma ray analysis software packages $^{4,5}$ and PIXE analysis software packages ${ }^{6,7,8}$.

\section{Methodology}

All authors of software codes that calculate energy spectra known to us were invited to participate. The participating codes are DEPTH ${ }^{9,10}$, GISA ${ }^{11,12}$, MCERD ${ }^{13,14}$, DataFurnace (NDF) ${ }^{15,16,17}, \mathrm{RBX}^{18,19}$, RUMP ${ }^{20,21}$, and SIMNRA ${ }^{22,23,24}$. More details are given in Table 1. Note that codes that analyse data using different methods, such as directly converting the yield to concentration values ${ }^{25}$ or other alternative methods such as artificial neural networks ${ }^{26}$ were not considered.

While it was understood that many codes can only perform a subset of the simulations and analyses defined, the objective was to test and validate only those relevant aspects for which the code was specifically designed. Further details about the codes can be found in ref. 3. All codes were used by the authors, in some cases working together with close collaborators. MCERD is a Monte Carlo code in binary collision approximation that takes multiple collisions between incident ions and target atoms into account, while all other codes 
utilise versions of the standard simulation procedure first described by Ziegler et al. ${ }^{27}$, where ion trajectories are approximated by straight lines. Multiple collisions can be approximated by some codes as an additional energy broadening contribution, and some codes also calculate the yield due to double scattering. We note that DEPTH is geared towards the calculation of energy spread, and not towards simulation of energy spectra.

From the multitude of physical effects and processes that can be investigated, we decided to test the ability to correctly:

(1) Extract film thicknesses and compositions of multilayered structures with abrupt interfaces, but which have complex, overlapping spectra.

(2) Extract hydrogen and deuterium concentrations and depth profiles.

(3) Model Rutherford cross-section screening corrections.

(4) Model sharp nuclear reaction resonances.

(5) Model multilayered structures with interdiffused interfaces.

(6) Model multiple and plural scattering effects.

(7) Model surface and interfacial roughness.

(8) Model resolution broadening as a function of depth.

The intercomparison exercise was divided into two main tasks: the first task included pure simulations only, done by each code for well-defined sample structures, well-defined experimental conditions, and well-defined physics. A set of five sample structures was defined, shown in Table 2, for which a total of 28 different simulations were selected, shown in Table 3. The objective was to use common grounds to unambiguously quantify differences between the different simulations of the underlying physics and physical processes. All software should input exactly the same experimental parameters, material properties, stopping 
power database and use the same differential cross-sections. All inputs were fixed. Simulated spectra were then produced by each code and compared. The calculations reported by each code are listed in Table 4. Note that absence of any given calculation does not mean that the code in question is not able to do it, but simply that it was not reported.

The second task considered the analysis of experimental data. The objective was to determine the full potential of the codes using their entire programmed science, algorithms and models. The authors had no constraints, and might freely choose any stopping power database and differential cross-sections, and were free to vary any scaleable parameters to obtain a best fit between the simulated and measured spectra. A simulated spectrum was then produced for the relevant measurement. All final parameters, databases, differential crosssections, physics used, ad-hoc procedures, etc must be specified to enable a proper evaluation of the science that contributed to successes. The experiments are briefly described in Table 5 . Table 6 lists the analyses reported by each code. Note that absence of any given analysis does not mean that the code in question is not able to do it, but simply that it was not reported.

The IAEA organised a meeting between the participants in October 2005, where the first results were reported and compared with each other. During that meeting, the participants had the opportunity to correct mistakes or to present improved calculations. Some participants still corrected or improved their calculations later on. It is the final results that are presented here, since the purpose of this work is to report on the current state of the codes, including all their best capabilities.

Finally, while it was agreed that the stopping powers to be used would be SRIM ${ }^{28}$ version 2003.26, GISA could not implement this on time for the exercise, and therefore used SRIM $1991^{29}$. 


\section{Results - calculation of theoretical spectra}

We will not report on all the calculations done, since some of those defined in Table 3 do not include extra physics or algorithms. They test, for instance, the capability to include different experimental configurations, or electron screening.

\subsection{Simulations of simple RBS spectra}

The spectra calculated for Structure 1, Calculation 1, are shown in Fig. 1. This will be referred to here as the "baseline" calculation: the structure considered is $\mathrm{Si} / 200 \mathrm{~nm} \mathrm{SiO} 2 / 50 \mathrm{~nm} \mathrm{Au}$, measured with a $1.5 \mathrm{MeV}{ }^{4} \mathrm{He}^{+}$beam detected with a $16 \mathrm{keV}$ FWHM resolution detector located at a $150^{\circ}$ scattering angle, for entrance and exit angles $60^{\circ}$ and $30^{\circ}$ (angles are always given respective to the sample normal, except where explicitly stated otherwise), respectively. The codes considered Bohr straggling ${ }^{30}$ (with propagation of straggling in thick layers, the so-called Tschalär effect ${ }^{31,32,33}$ in those codes that include it, which are DEPTH, NDF, and SIMNRA), unscreened Rutherford cross sections, and SRIM03 stopping except for GISA, which used SRIM91. All codes calculate nuclear stopping in this and all other simulations. All codes did this calculation. In general terms, the results are similar for all codes. The single largest difference is the cut-off energy at which the codes stop the calculation. This is highest for MCERD, since the Monte Carlo calculations become very inefficient for low beam energies. In any case, the low energy region is often disregarded in data analysis, and was not the point of this calculation.

However, some important differences do exist. The Au signal is shown in Figure 2, where it is clear that RBX calculates a smaller straggling than the other codes. $1.5 \mathrm{MeV}{ }^{4} \mathrm{He}$ in $\mathrm{Au}$ is close to the stopping power maximum, so that propagation of straggling in thick 
layers (Tschalär effect) is negligible in this case and straggling can be approximated by the simple Bohr straggling formula ${ }^{30}$ for the Au layer in the given geometry. It can be shown that $\mathrm{RBX}$ is calculating too little straggling in this case. Also, the Si and $\mathrm{O}$ signals are shown in Figure 3, and GISA produces a different calculation, as expected since it uses different stopping powers. A simulation made with NDF using the same stopping reproduced the GISA simulation.

It is clear that in this baseline case, the largest differences, besides the low energy cutoff and the calculated straggling, are due to the stopping power data base used, with smaller differences being due to some differences that exist in the actual physics considered (the only stated difference is to consider or not the Tschalär effect) or in their implementation in the codes $^{3}$. A quantitative comparison of the results is discussed in detail in Section 5.

Calculation 4 tests the capability of simulating very sharp edges, using the baseline but with $3 \mathrm{keV}$ FWHM resolution and no straggling. As the energy width of each channel in the calculation is also $3 \mathrm{keV}$, careful convolution with the resolution is required. The results for the back edge of the Au signal are shown in Figure 4. All the codes make a more or less smooth transition, albeit with differences in the details. NDF, RUMP, and SIMNRA are very close to each other.

\subsection{RBS: continuous profile}

Calculation 27 tests the ability to simulate a continuous profile, in this case a Gaussian distribution of Ge in $\mathrm{Si}$. The results shown in Figure 5 suggest that all codes are equivalent, but a close up of the Ge peak in Figure 6 reveals that RBX differs from the other codes in the tails of the distribution, possibly due to round-off errors. 


\subsection{RBS/Channelling}

Calculation 28 tested the capability of simulating channelling. The calculations are for sample 5, which is a $1 \times 10^{16}$ at $/ \mathrm{cm}^{2}$ Ge implant into bulk (100)Si. The Ge was taken as $100 \%$ substitutional, and a point defect distribution in the $\mathrm{Si}$ was assumed, following the $\mathrm{Ge}$ distribution but with a $2 \%$ maximum concentration.

Only RBX submitted results, as it is the only participating code that implements calculations of channelled spectra based on theory ${ }^{19}$. The dechannelling is calculated following the theory in ref. 34 . The ratio between the channelled to random stopping power was taken to be 0.88 .

Some of the other codes can, to some extent, implement ad-hoc corrections to the yield and to the stopping power of random materials in order to approximate channelled spectra, but these corrections are not related to actual physical properties of a given crystalline structure or of a given defect distribution.

The calculations are shown in Figure 7. For comparison, both the random spectrum, and the channelled spectrum from pure $\mathrm{Si}$, as calculated by RBX, are shown. The minimum yield calculated for the $\mathrm{Si}$ surface $(1500-1550 \mathrm{keV})$ and at the Ge peak are $2.1 \%$ and $4.3 \%$, respectively.

A Monte Carlo simulation of the same system was made with the code BISIC ${ }^{35}$. This is not a code designed for IBA data analysis in general, but specifically for analysis of $\mathrm{RBS} /$ Channelling spectra in the $\mathrm{Si}, \mathrm{SiC}$, and $\mathrm{Si}_{\mathrm{x}} \mathrm{Ge}_{1-\mathrm{x}}$ crystalline systems. The results are also shown in Figure 7. The agreement is surprisingly good, even considering the differences in the width of the Ge signal and of the defect distribution in the $\mathrm{Si}$, and in the height of the $\mathrm{Si}$ surface peak. Both codes assumed a perfect (unreconstructed) surface with the Si bulk lattice constants. 


\subsection{EBS and sharp resonances}

The next four examples test the capability of modelling non-Rutherford cross sections in general and resonances in particular. The first two test the Si(p,p)Si cross section, which has a fairly broad resonance at $1672 \mathrm{keV}$, with $1.4 \mathrm{MeV}$ and $1.8 \mathrm{MeV}$ proton beams in Calculations 13 and 14, respectively. The second two test the much sharper ${ }^{16} \mathrm{O}(\alpha, \alpha){ }^{16} \mathrm{O}$ resonance at $3.031 \mathrm{MeV}$ with a $3.15 \mathrm{MeV}{ }^{4} \mathrm{He}$ beam, with and without straggling in Calculations 15 and 16, respectively. In this sense, these examples are limited, since they do not include the calculation of a buried sharp resonance, which is the really difficult test case 36. In what follows we shall show only the resonance signal, except for calculation 13 (1.4 $\mathrm{MeV}$ protons), where there is no resonance. In all cases the cross sections were calculated with the code SigmaCalc ${ }^{37,38,39}$ developed by Dr. Alexander Gurbich.

Calculation 13, for 1.4 MeV protons, is shown in Figure 8. Good agreement is obtained. For $1.8 \mathrm{MeV}$ protons, the $\mathrm{Si} 1672 \mathrm{keV}$ resonance (calculation 14), is detected at about 1350 $\mathrm{keV}$ and is shown in Figure 9. The NDF and SIMNRA curves are virtually undistinguishable, with GISA being very close to them. RUMP leads to a slightly broader resonance, and DEPTH and RBX even more so. DEPTH and RBX put the oxygen signal $(1400 \mathrm{keV})$ at slightly higher energies than the other codes.

Calculations for $3.15 \mathrm{MeV}{ }^{4} \mathrm{He}$ without and with straggling are shown in Figure 10 and Figure 11, respectively. The codes have a different treatment of the cross section, which is input as an energy/cross section table. RUMP uses the integral cross section with a spline interpolation. NDF treats the values in the table as steps of a histogram, each one representing the energy interval given by half the difference to the neighbouring table points. The cross section is considered constant in each interval, and integrated over the internal layer being 
considered. DEPTH, RBX and SIMNRA use integrated cross sections with linear interpolation between the tabulated values. Each method has advantages and disadvantages, particularly considering that experimental cross sections, ad-hoc fitting functions based on experimental data, and semi-empirical calculation models, are in fact not completely equivalent. This discussion is quite involved, and is beyond the scope of this paper.

Without straggling (Figure 10), NDF and RUMP lead to very similar results, while SIMNRA is broader, and DEPTH and RBX seems to be shifted to higher energies. DEPTH calculates an area higher than the other codes.

When straggling is taken into account, NDF becomes broader than RUMP and SIMNRA. The reason is that NDF takes into account the effect of the energy spread of the beam before scattering ${ }^{36,40}$, by calculating correctly both the cross section for scattering at each depth (which is an average of the energy-dependent cross section over the beam energy distribution), and the average beam energy after scattering (which depends on the beam energy distribution before scattering in relation to the shape of the resonance), both of which effects require the calculation of two integrals for each depth of scattering. The first effect makes the resonances broader, while the second makes them sharper. The net effect is still a broadening of the resonance, which becomes important at any particular depth when the beam energy spread at that depth is comparable to the resonance width.

DEPTH and RBX calculate the correct cross section for scattering at each depth taking the energy spread before scattering into account, but not the correct average energy after scattering, and thus produce a resonance broader than the other codes. RUMP and SIMNRA did not consider the effect of energy spread before interaction.

\section{$3.5{ }^{4} \mathrm{He}$ ERDA}


ERDA spectra using a $1.8 \mathrm{MeV}{ }^{4} \mathrm{He}$ beam corresponding to Calculation 18 and Calculation 19 are shown in Figure 12 and Figure 13, respectively, for Sample 6 (Si bulk / $\mathrm{CD}_{2} 150 \mathrm{~nm} / \mathrm{C}^{1} \mathrm{H}_{2} 150 \mathrm{~nm} / \mathrm{CD}_{2} 150 \mathrm{~nm}$, considering the polymer density $\left.1 \times 10^{23} \mathrm{at} / \mathrm{cm}^{3}\right)$. They differ only in the fact that the first used Rutherford cross sections, and the second uses scattering cross sections for the $\mathrm{H}$ isotopes determined by V. Quillet ${ }^{41}$. In both cases, all calculations are very similar. RBX and RUMP seemingly did not calculate the signal due to the forward scattered beam. DEPTH calculated a slightly different energy loss for the backscattered signal. Finally, the signal edges are sharper in the RBX and RUMP calculations than in the other codes, for both Calculations 18 and 19, while being different from each other. A quantitative comparison of the results for Calculation 18 is discussed in detail in Section 5 .

\subsection{Heavy ion RBS and ERDA, including multiple scattering}

All codes simulated Calculation 9, which is for $3.5 \mathrm{MeV}^{7} \mathrm{Li}^{+}$, all other parameters equal to the baseline. The results are shown in Figure 14. The difference seen for GISA is due to the stopping power data base used, SRIM91, while the other codes used SRIM03. The large difference is due to the large evolution in knowledge about the stopping of ${ }^{7} \mathrm{Li}^{+}$and other heavy ions that occurred in the last two decades. The differences within the group that used SRIM03 are small, which shows that the basic algorithms used are correct. RBX calculates slightly less straggling than the other codes using SRIM03 stopping. A quantitative comparison of the results is discussed in detail in Section 5.

The results for Calculation 10 are shown in Figure 15. This is $50 \mathrm{MeV}^{127} \mathrm{I}^{10+}$ on Structure 1, forward scattering with detection of recoils. Bohr straggling and a constant 200 $\mathrm{keV}$ energy resolution were considered. MCERD, NDF and SIMNRA all give almost 
identical results, except on the back edges of the Au related signal (both Au recoils at $23 \mathrm{MeV}$ and ${ }^{127} \mathrm{I}$ backscattered from $\mathrm{Au}$ at $30 \mathrm{MeV}$ ). RUMP and RBX calculate different straggling, most visible at the oxide/substrate interface. DEPTH and RBX also leads to some differences in spectral height and width, which could to be due to differences in the handling of the stopping power.

Calculation 11 is the same as 10, but a realistic time-of-flight resolution of 300 ps for 50 cm flight path was considered. Only MCERD and SIMNRA implement this, and the results are shown in Figure 16.

Calculation 12 is the same as 10 , but including multiple scattering. This is a very hard case due to the incident heavy ion, heavy substrate, and low energy: Multiple scattering plays an important role, including changes in total yield ${ }^{3,42}$. The results are shown in Figure 17. First of all, it is clear that when the full ion-target interaction is taken into account, as in the Monte Carlo code MCERD, the results are substantially different. This is probably one case where the traditional spectrum generation methods, which assume straight ion trajectories and include multiple scattering only as an additional broadening contribution, become inadequate. However, the main difference is due to the ${ }^{127} \mathrm{I}$ ions backscattered from the Au layer, while the recoil signals are similar in MCERD code and in the other codes. One should note that these kind of spectra are usually detected with mass sensitive detectors where direct comparison of full energy spectra is not made.

Second, to calculate the energy spread of the detected ions several analytical codes (DEPTH, RBS, SIMNRA) implement the same theory of multiple scattering ${ }^{9}$. NDF uses DEPTH automatically in run-time. RBX and SIMNRA contain independent implementations of this theory. However, DEPTH and RBX produce a spectral shape closer to that of MCERD than NDF or SIMNRA do, because they included a better description of the shape of the energy distribution, which is non-Gaussian ${ }^{9}$. SIMNRA and NDF can produce spectra which 
are closer to the MCERD result, if they additionally include plural scattering (approximated by dual scattering).

\subsection{NRA}

Calculation 20 is shown in Figure 18. It is NRA with a $1 \mathrm{MeV}^{3} \mathrm{He}$ beam and with the reactions $\mathrm{d}\left({ }^{3} \mathrm{He},{ }^{4} \mathrm{He}\right) \mathrm{p}$ and $\mathrm{d}\left({ }^{3} \mathrm{He}, \mathrm{p}\right){ }^{4} \mathrm{He}$, on the same sample as in Calculations 18 and 19, and also with the same stopper foil, but measured at a $170^{\circ}$ scattering angle and normal incidence. The cross section was taken from ref. 43. Only NDF and SIMNRA did this calculation. The low energy signal corresponds to ${ }^{4} \mathrm{He}$ being detected, while the high energy signal is for detected protons. The difference in the alpha and proton yields calculated is $0.2 \%$ and $0.6 \%$, respectively. There are differences in the straggling calculated for the ${ }^{4} \mathrm{He}$; nevertheless, agreement is considered good, taking into account that the ${ }^{4} \mathrm{He}$ loses almost all its energy in the foil before being detected. Details of the straggling calculations at very low energies could be responsible for the differences found.

Calculation 21 is shown in Figure 19. It is NRA with a $1 \mathrm{MeV}$ deuterium beam with the reaction ${ }^{14} \mathrm{~N}\left(\mathrm{~d},{ }^{4} \mathrm{He}\right){ }^{12} \mathrm{C}$, for a bulk $\mathrm{Fe}_{4} \mathrm{~N}$ sample, measured at a $170^{\circ}$ scattering angle and normal incidence. Only NDF and SIMNRA did this calculation. The interesting point is the kinematics of this reaction, which requires careful programming (see e.g. ref. 44). At energies above $550 \mathrm{keV}$ the kinematics is normal, i.e. the energy of the reaction product decreases with decreasing projectile energy. At energies below $550 \mathrm{keV}$ the kinematics is inverted, and the energy of the ejected ion increases with decreasing projectile energy. Agreement is excellent, except at the low energy tail where NDF calculates yield down to slightly lower energies.

\subsection{Geometric straggling, multiple scattering, plural scattering}


Calculations 22 to 24 were intended to test the separated effects on energy spread of geometric straggling and multiple scattering. Unfortunately, for the particular conditions chosen, in the region of the $\mathrm{Au}$ and $\mathrm{SiO} 2$ films, Bohr straggling is the largest contribution to energy spread. Geometric straggling is very small, and multiple scattering only leads to an energy spread deeper in the Si substrate. Thus Calculations 22 to 24 all lead to fairly similar results.

Calculation 24 is shown in Figure 20. It is for the baseline experimental conditions, but considering all effects that lead to energy spread, including the Chu correction ${ }^{45,46}$ to Bohr straggling, geometric straggling and multiple scattering. NDF and SIMNRA produce a slightly sharper Au back edge than DEPTH, possibly because they use a Gaussian shape for the energy spread, while DEPTH uses more realistic distribution shapes. The actual contribution of multiple scattering to energy spread as calculated by DEPTH and SIMNRA (and also MCERD) is actually very similar ${ }^{47}$. As mentioned previously, NDF uses a version of DEPTH at run time to calculate all these energy spread contributions.

Only NDF ${ }^{48,49}$ and SIMNRA ${ }^{50}$ can calculate double scattering, which is the main contribution to plural scattering. The results for Calculation 26 are shown in Figure 21. Given that the calculations required are complex and involve a definition, to some degree arbitrary, of which events effectively constitute double scattering, agreement is surprisingly good. Calculation 25 involves double scattering at grazing angle, which leads to further difficulties 48.

One should note that the codes that can calculate geometric straggling and multiple scattering for RBS also do it for the other techniques. This is not the case for double scattering, that is implemented only for RBS in both NDF and SIMNRA. 


\subsection{Pulse pileup calculation}

Only NDF, RUMP and SIMNRA submitted results for Calculation 7, which is the baseline with pulse pileup taken into account, considering a detector with $5 \mu$ s shaping time $\mathrm{T}_{\mathrm{W}}$ and no pileup rejection circuit. The results are in Figure 22. NDF and SIMNRA codes use

implementations of the same basic algorithm ${ }^{51-53}$, and considered that the time required for the pulse to reach a maximum value $T_{p}$ is related to the shaping time of the amplifier via $T_{\text {pulse }}$ $=1.9 \mathrm{~T}_{\mathrm{W}}$. While NDF and SIMNRA approximate the pulse shape as parabolic, RUMP approximates it as triangular. The agreement between the simulations can be considered excellent, particularly when compared with the simulation without pileup, also shown (SIMNRA Calculation 1). The difference between RUMP and the other two codes is assigned to the different shape of the pulses considered. As for NDF and SIMNRA, the differences could be due to different implementations of the basic algorithm, but the most likely cause is that the pile-up calculation is based on the calculated spectrum without pile-up, and NDF extends the calculation to lower energy values than SIMNRA. As the yield at those energies is high, this should lead to a higher pile-up, as seen in Figure 22.

Only NDF and SIMNRA submitted results for Calculation 8, which is the baseline with pulse pileup taken into account, considering a detector with $5 \mu$ s shaping time and a pileup rejection circuit with $0.5 \mu$ s rejection time. The results, shown in Figure 23, are very close.

Pulse pileup affects all the techniques, not only RBS, and the algorithms to calculate it are the same. Differences arise depending on the detection and electronics system.

\section{Results - analysis of experimental data}


MCERD did not participate in this part of the intercomparison exercise. DEPTH is not designed primarily for analysis of experimental data, and only did the simulation of the amorphous silicon sample.

\subsection{Amorphous silicon}

Every code should be able to reproduce a $2 \mathrm{MeV}^{4} \mathrm{He}$ RBS spectrum from amorphised Si. The sample was produced and measured at the CNR-IMM-Sezione di Bologna, as described in detail in ref. 54, and the details of the RBS experiment are given in ref. 55. Of all the data analysed in this intercomparison exercise, this is the set-up described in most careful detail and with best accuracy of the experimental parameters.

The beam was $2 \mathrm{~mm}$ wide and $1 \mathrm{~mm}$ high, with a $0.03^{\circ}$ divergence. The beam current and fluence were $28 \mathrm{nA}$ and $46.0(5) \mu \mathrm{C}$, respectively. The collection and live time were 1642 and $1625 \mathrm{~s}$, respectively. The amplifier had a gain of $3.840(8) \mathrm{keV} / \mathrm{ch}$, determined without taking the pulse height defect (PHD) into account, and a $0.5 \mu$ s shaping time. A $16 \mathrm{keV}$ at FWHM circular detector with 5.01(2) mm diameter was located at a 150.0(2) scattering angle, at a distance of $100.5(3) \mathrm{mm}$ from the sample, for a 1.95(2) msr solid angle. The angle of incidence was $0.0(1)^{\circ}$. No pile-up rejection was used. The measurement of the stopping power depends at first order on the electronic gain, and this was measured very precisely using a 7 point correlation. The effect of the PHD correction can be calculated ex post hoc using the formalism of Lennard et al. ${ }^{56}$; using a dead layer equivalent thickness of $25 \times 10^{16} \mathrm{Si} / \mathrm{cm}^{2}$ we find the gain changing by $0.22 \%$. This will be a (small) systematic error on the determination of the stopping power.

All the simulations are shown in Figure 24. They are almost undistinguishable at the Si surface edge and in the yield in the near-surface region. These are the regions that are 
normally considered in analysis of real data, as the low energy yield is notoriously difficult to calculate correctly. Differences between the different calculations start to appear at energies below around $600 \mathrm{keV}$, which are mostly due to the different stopping powers used (GISA used SRIM91 ${ }^{29}$ scaled by a factor of 0.97 , DEPTH used SRIM95, RUMP and SIMNRA used SRIM03 ${ }^{28}$, and NDF used Barradas ${ }^{57}$ which is equivalent to KKKNS*1.02 ${ }^{58}$ ). All codes calculate nuclear stopping in this and all other analyses of real data. Different implementations of straggling, and eventually pile-up and other algorithmic issues can also lead to differences. Table 7 shows details of the different calculations. Some of us did different simulations using different stopping power data bases, and altering very slightly the beam fluence and the detector resolution. No large differences are noted. In general, we consider that the results are excellent, validating the correctness of the codes.

We calculated the function $\chi^{2}=\frac{1}{n} \sum_{i}\left(\text { data }_{i}-\text { simulation }_{i}\right)^{2} /$ data $_{i}$, where $n$ is the number of points over which the sum is made, for different energy windows. The first window is from 250 to $1150 \mathrm{keV}$, encompassing almost all the $\mathrm{Si}$ signal, and the second window is from 800 to $1100 \mathrm{keV}$, corresponding to the Si signal at energies above the oxygen signal. In both cases the Si surface edge signal was excluded, because small differences in defining what the energy of a channel is, can lead to large changes in $\chi^{2}$. The third window, 1250-1900 keV, includes the signal above the Si surface barrier, where only pile-up is expected to be observed. For Gaussian distributed data, the expectation value of the $\chi^{2}$ for a perfect simulation is 1 .

In the case of GISA, the factor used to multiply the SRIM91 stopping power was adjusted to obtain a ratio between the simulated and experimental yield in the $800-1100 \mathrm{keV}$ energy window equal to 1 . In this case, the $\chi^{2}$ statistic is not meaningful for GISA. 
The results are shown in Table 8 . The overall best $\chi^{2}$ is obtained by DEPTH, due to choosing the best energy dependence of stopping power for silicon. At the same time, DEPTH has the worst $\chi^{2}$ in the near surface region. On the contrary, SIMNRA has the best $\chi^{2}$ at high energies, with NDF a close second, but the worst overall one, with NDF being almost as bad. GISA and RUMP obtain fairly good $\chi^{2}$ values in both energy windows. Given that the low energy signal is often disregarded in data analysis, we consider that all the codes obtain excellent agreement in the important high energy region of the Si signal. Finally, while DEPTH and GISA did not calculate pile-up, the calculations made by NDF, RUMP and SIMNRA are approximately equivalent.

\subsection{Certified Sb implant}

The sample is a $15 \mathrm{~mm}$ square piece of the certified reference material IRMM0001/BAML003, provided by the European Institute for Reference materials and Measurements. It is was made by implanting Sb into a (100) Si wafer with a $90 \mathrm{~nm}$ surface oxide layer. The material has a certified retained $\mathrm{Sb}$ content (uncertainties given at one standard deviation) of $48.1(3) \times 10^{15} / \mathrm{cm}^{2}$ (which is a $0.6 \%$ uncertainty) ${ }^{59}$. The oxide thickness and interface quality are not certified. The sample was amorphised to a depth of about $630 \mathrm{~nm}$ with a $500 \mathrm{keV} 5 \times 10^{15} \mathrm{Si} / \mathrm{cm}^{2}$ implant on a stage cooled by liquid nitrogen.

The sample was measured at the University of Surrey Ion Beam Centre with a 1.557(2) $\mathrm{MeV}^{4} \mathrm{He}$ beam, detected simultaneously by two detectors, located at $172.8(2)^{\mathrm{o}}$ and $149.2(2)^{\mathrm{o}}$ scattering angles with electronic gains of $3.388(10)$ and $3.545(10) \mathrm{keV} / \mathrm{ch}$ and energy resolutions of 21 and $14 \mathrm{keV}$ respectively. The amplifiers had $0.5 \mu$ s shaping time and pileup rejection with a time resolution of about 500ns was used. Further details can be found in ref. 60 . 
The parameter to be derived was the Sb retained fluence. The amorphised silicon substrate was used to determine the charge - solid angle products of the detectors. Some participants also reported the $\mathrm{Sb}$ peak depth $\mathrm{R}_{\max }$ and width $\Gamma$ (FWHM), and also the thickness $\mathrm{t}_{\mathrm{SiO} 2}$ of the oxide layer. The experimental uncertainty of the $\mathrm{Sb}$ from counting statistics is $0.2 \%$, with a maximum uncertainty of the experiment is $0.8 \%{ }^{60}$, including all other factors except for the effect of stopping power.

The data can be analysed by fitting an arbitrary continuous distribution of $\mathrm{Sb}$ throughout the sample (including in the oxide), where the area of the fitted Sb signal matches the area of the data. This creates a continuous profile that is reported as concentration versus areal depth. Alternatively (and equivalently), the data can be replotted (with pileup subtracted) on a concentration vs. areal depth scale, using the energy loss function (and energy dependence as a function of depth) determined from the fit. The area of this signal can be directly interpreted as the $\mathrm{Sb}$ fluence. This procedure is independent of the $\mathrm{Sb}$ peak depth $\mathrm{Rp}$ and width values, and leads to very high accuracy in the Sb fluence determined. The different codes used variations of this procedure.

The results are given in Table 9. SIMNRA and RUMP analysed the two spectra independently, obtaining two different values for the $\mathrm{Sb}$. We show the average value. NDF did both independent and joint analyses. The other codes derived one single value. All the codes obtain values close to the certified value. The uncertainty shown for NDF, $0.06 \%$, was obtained from a Bayesian inference analysis ${ }^{16}$, and reflects only the total expected counting statistics uncertainty for the $\mathrm{Sb}$ signal $(0.05 \%)$. Note also that the $\mathrm{Sb}$ fluence determined is directly affected by the Si stopping power used. Some codes also did complementary analyses using different sets of stopping powers. Various $\mathrm{Sb}$ fluence values were reported, with differences up to $2 \%$ consistent with the differences in the stopping power databases. 
The standard deviation of the reported values using SRIM03 stopping is $0.055 \times 10^{15}$ $\mathrm{Sb} / \mathrm{cm}^{2}$, which is $0.11 \%$ in relative terms. The average value is $48.015 \times 10^{15} \mathrm{Sb} / \mathrm{cm}^{2}$, which is $-0.18(11) \%$ away from the certified value. This is an extraordinary agreement not only amongst the codes, but between the codes and the known Sb amount, which means that RBS can be used to obtain accuracies in the region of $0.2 \%$ in the determination of fluences, if best practice is used both in performing the experiment and in analysing the data.

It also means that the Si stopping power in SRIM03 is consistent with the certified standard to the accuracy of the certified standard $(0.6 \%, 1 \sigma)$. We point out here that this represents a significant improvement in the accuracy with which the Si stopping powers are known, since the current uncertainty on these values is no better than $1 \%^{54,56}$, and there is no independent confirmation of that accuracy. At present we have to cite an uncertainty of $2 \%{ }^{58}$ in critical work. SRIM2003 itself has no critical traceability for particular stopping power values.

Table 9 also shows the ratio of the results obtained independently for the two detectors, which should be unity, and which has an uncertainty from counting statistics of $0.12 \%$.

The pile-up calculated in the region of the Si substrate used for absolute normalisation is around $-0.3 \%$ and $-0.8 \%$ of the calculated yield for the $172.8^{\circ}$ and $149.2^{\circ}$ detectors, respectively. NDF, RUMP, and SIMNRA all included pile-up in the analysis. Double scattering in the same region, as calculated with NDF, is $+0.25 \%$ and $+0.28 \%$ of the single scattering. Inclusion of double scattering in the other codes would have led to a slightly lower charge - solid angle product required to fit the bulk Si yield, by about 0.2 to $0.3 \%$, and consequently to an $\mathrm{Sb}$ fluence higher by the same amount. The electronic screening correction for $\mathrm{Sb}$ is $1.3 \%$ of yield, and must be included. The difference between the L'Écuyer ${ }^{61}$ and Andersen ${ }^{62}$ formulations is however only $0.04 \%$ in this case. It is thus clear that inclusion or 
not of these effects, and their different treatment in the various codes, could justify the differences found between the codes. Note that the $\mathrm{Sb}$ content in this sample is certified only at $0.6 \%(1 \sigma)$, so that even without the double scattering correction the Si stopping power for this beam energy is validated at this accuracy.

Values for the range $\mathrm{Rp}$ and width of the $\mathrm{Sb}$ distribution, together with the oxide thickness, are also given in Table 9. These parameters are only reported for information: the determination of the $\mathrm{Sb}$ fluence does not depend on them. $\mathrm{Rp}$ in some cases was simply taken as the centre of the layer with maximum $\mathrm{Sb}$ concentration. In other cases a semi-Gaussian was fitted to the distribution. The standard deviation of the $\mathrm{Sb} \mathrm{Rp}$ values is $0.2 \times 10^{17}$ at. $/ \mathrm{cm}^{2}$ which is $2.2 \%$ in relative terms, much larger than that for the Sb fluence, which is not surprising given that the depth resolution is $1.5 \times 10^{17}$ at. $/ \mathrm{cm}^{2}$. Note that the position of the peak of a distribution in an RBS spectrum can be determined with a precision better than the nominal depth resolution ${ }^{63}$.

\subsection{Hafnium oxide on silicon}

The sample is a thin hafnium oxide layer of unknown composition and with unknown impurities, on silicon. It was measured at the Accelerator Laboratory of the University of Helsinki with a $2.5 \mathrm{MeV}{ }^{4} \mathrm{He}$ beam with $15^{\circ}$ angle of incidence, detected at a $165^{\circ}$ scattering angle. Not much more was known about the sample, which makes this a good test case since that is how routine RBS analysis is often done. The data and the simulations made by the different codes are shown in Figure 25.

GISA, NDF and SIMNRA used for the $\mathrm{O}$ cross section SigmaCalc ${ }^{37}$ results. RUMP used an analytical representation of the resonance from a model by Cameron ${ }^{64}$. SIMNRA used for the $\mathrm{C}$ cross section the data of Feng et al. ${ }^{65}$. GISA used SRIM1991 ${ }^{29}$ stopping for all 
elements. NDF used Barradas et al. ${ }^{57}$ for the Si stopping, and SRIM03 ${ }^{28}$ for the other elements. RUMP and SIMNRA used SRIM03. NDF, RUMP and SIMNRA calculated the effect of Andersen electron screening in the cross section.

Pile-up leads to a maximum change in the Hf yield of $-0.22 \%$. Only GISA did not take this into account. NDF calculated the contribution of double scattering. However, this was not enough to reproduce the background seen at energies below the Hf peak. This background could be due to plural scattering, slit scattering, some heavy impurity in the Si substrate, or other unknown causes ${ }^{66}$. NDF, RUMP, and SIMNRA introduced an ad-hoc contribution to the yield to obtain a good fit to this background (and to the Si bulk signal). In the case of SIMNRA, this was done by introducing 0.078 at.\% Hf in the Si. NDF and RUMP created an artificial background manually, which is then added to the simulated total scattering. GISA did not introduce this ad-hoc background in the region of the $\mathrm{Zr}$ signal, and thus determined the $\mathrm{Zr}$ content by simulating the height of the $\mathrm{Zr}$ signal relative to the background, which is as valid and accurate a method. GISA did introduce an ad-hoc background in the region of the $\mathrm{O}$ signal, to reproduce the Si signal in that region. Note that ad-hoc backgrounds and corrections are just a convenient way to extract the information required. They do not have a physical basis in themselves and any information the spectrum may have relating to the affected part of the signal is effectively disregarded.

The most relevant parameters are given in Table 10. The shape of the $\mathrm{O}$ signal (Figure $25 \mathrm{~b}$ ) is due to a resonance in the scattering cross-section at $2484 \mathrm{keV}$. First of all, while all codes introduced one hafnium oxide film with a $\mathrm{Zr}$ contamination, NDF also considered a natural oxide layer on top of the Si substrate, and SIMNRA introduced a contamination layer on the surface of the sample. There seems to be a rather large variation on the values found for the thickness of the hafnium oxide layer, which is $870(28) \times 10^{15}$ at. $/ \mathrm{cm}^{2}$, i.e. the variation amongst codes is $3.2 \%$. However, the layer thickness is mostly determined from the total Hf 
and $\mathrm{O}$ content. The total Hf content is $296(4) \times 10^{15} \mathrm{Hf} / \mathrm{cm}^{2}$, which is a $1.4 \%$ variation. The variation expected from counting statistics only is $0.2 \%$. For the $\mathrm{O}$, one should consider the total amount derived, including the oxygen in the surface and interfacial layers for SIMNRA and NDF, respectively. This leads to an average and standard deviation of 584(31) $\times 10^{15}$ $\mathrm{O} / \mathrm{cm}^{2}$, which is a $5.3 \%$ scatter amongst codes. However, if we consider only those codes (GISA, NDF, SIMNRA) that used the same cross section (SigmaCalc), then we obtain 599(5) $\times 10^{15} \mathrm{O} / \mathrm{cm}^{2}$, which is a $0.8 \%$ scatter. This is unexpectedly small since the counting statistics uncertainty is $4.5 \%$ for the $\mathrm{O}$ signal. All of the analysts have correlated the $\mathrm{Hf}$ and $\mathrm{O}$ signals thus trading a larger than expected uncertainty for the Hf signal for a smaller than expected uncertainty for the $\mathrm{O}$ signal. However, it is clear that the use of a different data base leads to the largest differences in the results produced by each code.

Finally, for the $\mathrm{Zr}$ impurity the results are $2.96(8) \times 10^{15} \mathrm{Zr} / \mathrm{cm}^{2}$, which is a $2.7 \%$ scatter, comparable to the $5.6 \%$ expected from the counting statistics.

\subsection{Cobalt/rhenium multilayer}

Multilayers with nominal structure Si bulk / Re $5 \mathrm{~nm} /(\text { Co } 2 \mathrm{~nm} / \operatorname{Re} 0.5 \mathrm{~nm})_{15}$ were produced by magnetron sputtering, and analysed at ITN, Sacavém ${ }^{67,68}$. The layers are not atomically flat, with roughness values in the order of a fraction of nm. The RBS analysis was done using a $1.0 \mathrm{MeV}{ }^{4} \mathrm{He}$ beam, detected at $160^{\circ}$ in the Cornell geometry. A set of six spectra were collected, from near-normal incidence to grazing incidence, with angles with respect to the sample surface down to $6^{\circ}$.

The objective of this analysis is to test the capability to retrieve very complex layer structures, as well as roughness parameters. This information cannot be obtained by analysing each spectrum on its own. Only NDF and SIMNRA reported on this case. The two sets of 
simulations are shown in Figure 26, and the layer structure derived is given in Table 11. Note that for the layer thicknesses for layers 20-32 cannot be derived from the spectra, and the numbers are just assumptions. SIMNRA analysed the six spectra with the same layer structure except for the thickness of the surface $\mathrm{C}$ layer, which is a valid assumption given that at least part of the $\mathrm{C}$ is deposited during the measurement (made at pressure around $10^{-7}$ mbar). NDF made one single fit of the six spectra, and thus it used the same surface $\mathrm{C}$ thickness. Considering that these layers are ultra-thin (in particular, the Re layers correspond to 2 to 3 monolayers each), the agreement between the layer structures found is excellent.

The analysis made by both codes showed that some form of roughness must be present. However, it is difficult, and sometimes impossible, to determine from RBS alone the type of roughness present. NDF ${ }^{69,70}$ and SIMNRA ${ }^{71}$ implement different roughness models. NDF used a model where it is considered that the substrate is rough, with the presence of steps, and the subsequent layers are deposited conformally on top of these steps. Of all the models implemented in NDF, this is the one that best matches the other results known about this system ${ }^{67,68}$. The standard deviation of the height of the substrate features was determined as $0.61 \mathrm{~nm}$, with an average lateral width of $40 \mathrm{~nm}$. A fit assuming a wavy sample was also achieved, but it was not as good as that obtained with the rough substrate. SIMNRA, on the other hand, assumed also that the substrate is rough, not with steps but with a Lorentz distribution of the substrate surface angle with a FWHM of $0.3^{\circ}$.

\section{Validation of codes}

Here we shall give quantitative results on the differences between the calculations made by the different codes, that can be assigned to the codes themselves. This means that only those codes that use the same stopping, i.e. SRIM03, will be compared. We selected three 
case for comparison: the baseline, i.e. an RBS spectrum; Calculation 9, i.e. heavy ion RBS; and Calculation 18, i.e. ERDA.

For each one of these cases, we selected relevant features that can be compared quantitatively, such as total yield of separated signals, height of given plateaux, position and width of edges. To determine the position and width of edges, we used commercial software to differentiate the calculated spectra, and to fit Gaussians to each peak that corresponds to a given edge. This procedure leads to some error, particularly for the edge width, which is difficult to quantify and may be responsible for some of the differences found.

\section{$5.1{ }^{4} \mathrm{He}$ RBS}

The features selected for Calculation 1 were the $\mathrm{Au}$ total yield, the height of the plateaux for $\mathrm{Au}$ (in region $1240-1260 \mathrm{keV}$ ), $\mathrm{Si}$ in the $\mathrm{SiO}_{2}$ layer $(720-740 \mathrm{keV}$ ), $\mathrm{Si}$ in the substrate $(580-600 \mathrm{keV})$, and $\mathrm{O}(450-470 \mathrm{keV})$, and the position and width of all the relevant edges: right and left $\mathrm{Au}, \mathrm{Si}$ surface edge and $\mathrm{Si} / \mathrm{SiO}_{2}$ interface, and right and left $\mathrm{O}$.

The results are given in Table 12. For the yield and heights, the average and standard deviation values were calculated from the DEPTH, NDF, RBX, RUMP, and SIMNRA values. The MCERD results were not considered because the statistical nature of the MC calculations leads to an extra error. For the edge position and widths, the RBX results were also excluded from the calculation of the average and standard deviation values, due to the problems with straggling in this calculation seen in Figure 1.

For the yield and height calculations, the standard deviation amongst the different calculations is between 0.12 and $0.26 \%$. This is close to what can be achieved experimentally, and much better than the accuracy of the data bases used, particularly stopping power. Here, we must stress that the average is not the "correct" value. Finally, the results obtained with 
MCERD are extraordinarily close to the results obtained with the standard codes, which validates the Monte Carlo approach.

For the edge positions, agreement is obtained within 0.1 and $0.7 \mathrm{keV}$. Amongst the subset of codes NDF, RUMP, and SIMNRA, a $0.1 \mathrm{keV}$ standard deviation is obtained. MCERD leads to values consistently below the average, which could however be due to a

different definition of what an energy bin actually is. Please note that the PHD non-linearity ${ }^{56}$ can lead to a change in the edge positions. However, none of the codes considered this effect in these calculations, and thus the results are directly comparable, that is, the PHD nonlinearity is not responsible for the small deviations between the codes.

For the edge widths, the agreement is better for the higher energy edges. The $2 \mathrm{keV}$ standard deviation found for the lower energy edges is still smaller than the energy width of one channel, which is $3 \mathrm{keV}$ in this case, and could also be due to the analysis procedure. However, it can also be due to differences in the handling of the straggling.

\section{$5.2{ }^{7} \mathrm{Li}$ RBS}

The same features as for ${ }^{4} \mathrm{He}$ RBS were selected. For the yield and heights, the average and standard deviation values were calculated from the DEPTH, NDF, RBX, RUMP, and SIMNRA values. The MCERD results were not considered because the statistical nature of the MC calculations leads to an extra error. For the edge position and widths, the RBX results were also excluded from the calculation of the average and standard deviation values, due to differences in the straggling calculated. The results are given in Table 13.

For the yield and height calculation, the standard deviations are higher than for ${ }^{4} \mathrm{He}$ RBS, between 0.2 and $0.7 \%$. This is between 0.1 and $0.3 \%$ when calculated for the NDF, RUMP and SIMNRA subset of codes. MCERD shows the scatter of values expected for a 
Monte Carlo code, with deviations up to $2.6 \%$ in the low energy region where statistics are poorer. Nevertheless, these results validate the Monte Carlo approach.

For the edge position and width, again close agreement is reached amongst the codes. Note that here the energy width of a channel was $7 \mathrm{keV}$, so the errors in the determination of the edge widths are still less than half a channel, and again, could be due to the analysis procedure. The PHD correction is expected to be larger than for ${ }^{4} \mathrm{He}$ RBS, but as discussed in the previous section, none of the codes considered this effect in these calculations, and thus the results are directly comparable.

\section{$5.3{ }^{4} \mathrm{He}$ ERDA}

The features selected were the edge and width of the ${ }^{1} \mathrm{H}$ and ${ }^{2} \mathrm{H}$ signals, the total yield of the two ${ }^{2} \mathrm{H}$ signals (surface layer - high energy, and bottom layer - low energy) and of the ${ }^{1} \mathrm{H}$

signal. The bottom ${ }^{2} \mathrm{H}$ signal is not entirely separated from the ${ }^{1} \mathrm{H}$ signal, but the distinction is however clear enough. The limit between them was taken to be the channel where the yield is minimum.

For the yields, the average and standard deviation values were calculated from the DEPTH, NDF, RBX, RUMP, and SIMNRA values. For the edge positions and widths, RUMP and RBX were excluded because they show some marked differences, possibly due to straggling, as seen in Figure 12. The MCERD results were not considered because the statistical nature of the MC calculations leads to an extra error.

The results are given in Table 14. Agreement between 0.5 and $1.3 \%$ is obtained for the yield calculation. This is not good agreement, given that such differences are within what an accurate experiment can reach. For NDF, RUMP, and SIMNRA, agreement between 0.03 and $0.21 \%$ is obtained. 
For the edge positions agreement between 0.9 and $2.1 \mathrm{keV}$ is obtained (between 0.1 and $0.4 \mathrm{keV}$ for the NDF, RUMP, SIMNRA subset), while for the edge widths, agreement is slightly worse.

\section{Conclusions}

In this paper some of the particle-particle nuclear data analysis software codes available to the ion beam analysis community for thin film depth profiling have been compared and evaluated for the first time. In the first step of this exercise, a series of simulations were defined, testing different capabilities of the codes, for fixed conditions. In the second step, a set of real experimental data were analysed; the objective being to determine the full potential of the codes with no constraints.

Within the limits of their design the codes perform well, and the largest differences in the results arise from differences in the fundamental data bases used. All codes gave useful results in the case of simulations, and for experimental data evaluation all the software gave reliable results with acceptable errors. Some complex structures could be analysed by only a limited number of codes.

There are a number of subsidiary conclusions that should be stated. We did not compare extensively the physics or its implementation into the codes or any computational details. All the codes are very extensive, with the concomitant probability of algorithmic errors, which are recognised as notoriously difficult to correct. These errors can be in the implementation of the physics (for instance mismatched units; interchanging FWHM and standard variation; and many more, some only occurring when some specific features are used simultaneously), or in numerical algorithms (poor integration methods; faulty convolutions in the tails of the distribution or for very small FWHM values; adding millions of small numbers in single 
precision; and many more, some only occurring when some specific features are used simultaneously)

That completely different implementations of the physics (using different programming languages, different algorithms, and different general philosophy and structure of the codes) result in only small differences, and often give indistinguishable results, is very strong evidence for the reliability of the codes as a whole. The fact that there is excellent agreement between the single scattering codes and the Monte Carlo code is particularly encouraging.

Because IBA has well known physics, it is an ideal technique for use in standards or quality assurance work where traceable accuracy is critical. The present work has validated IBA codes for this purpose. In most important cases the demonstrable calculation accuracy of the codes can reach the $0.1 \%$ level. The exception is for non-Rutherford resonances, where significant differences between the codes exist.

The validity of the codes has been demonstrated not only for Rutherford backscattering with light ions but also for heavy ion RBS, non-Rutherford elastic backscattering and nuclear reaction analysis. HI-RBS is valuable for ultra-high sensitivity, and EBS for much thicker samples or for light element sensitivity. NRA is particularly useful for some light elements. A range of real effects such as pulse pileup, energy straggling and sample roughness can be shown to be treated correctly by the codes. Thus, we have shown that IBA spectra can be interpreted accurately for a very wide variety of samples, including samples of considerable complexity.

There is one case where the physics is not yet sufficiently well understood to be able to interpret scattering data quantitatively with single scattering codes. This is calculation 12 (Figure 17), which is heavy ion ERDA with multiple scattering, where the single scattering codes gave results inconsistent with the Monte Carlo code (which is known to agree reasonably well with experiment) for the backscattered ions. 
The channelling technique has been so far overlooked by most codes. The comparison of RBX results, which is the only traditional code for IBA data analysis that implements channelling calculations, with a dedicated channelling Monte Carlo code, BISIC, shows that excellent results can be obtained by traditional codes.

A standard sample with an $\mathrm{Sb}$ content certified to a $0.6 \%$ error was measured with a $0.2 \%$ experimental uncertainty, determining the charge - solid angle product from the a-Si yield using SRIM 2003 stopping powers for ${ }^{4} \mathrm{He}$ on Si for a beam energy around $1.5 \mathrm{MeV}$. The average of the $\mathrm{Sb}$ content values as determined with each code was $-0.18 \%$ away from the certified value, with a standard deviation of $0.11 \%$. Inclusion of extended physics, such as calculation of double scattering, can lead to still better agreement. It should be emphasised that the experimental uncertainty in the measurement of ${ }^{4} \mathrm{He}$ stopping in $\mathrm{Si}$ is currently $2 \%$ $57,58,72,73,74$. This analysis has now established that the SRIM03 tables correctly predict the backscattered yield for this beam in Si at this beam energy with an uncertainty of $0.6 \%(1 \sigma)$, which is the certified value of the Sb content of this sample.

The objective of this work was not to rank the relative strengths and weaknesses of the different programs and no such ranking has been produced. Other aspects, such as how easy each code is to use, the ability for semi or fully automatic data analysis, and data bases for stopping powers and cross-section data included, have not been evaluated. Nevertheless we believe we have provided the end user all the necessary elements to choose the most appropriate software for their specific needs.

This exercise was the first opportunity for code authors to compare and check their calculations in a systematic way. Many changes, corrections and improvements were made, often related to subtle details of the calculations. Better physical models and better implementations of the existing models were developed. The result has been improved codes 
available to the IBA practitioners. Finally, the calculations presented here are made available to the community ${ }^{75}$.

\section{Acknowledgements}

We would like to thank the IAEA for supporting this intercomparison exercise, and Dr. Alexander Gurbich for providing some scattering cross sections. Work is partially supported by the Hungarian OTKA grant No.: T 046238 and the UK EPSRC grant GR/R50097. 


\section{References}

1 World Survey of Accelerator Based Analytical Techniques, IAEA, Vienna, 2004. Available from: $<$ http://www-naweb.iaea.org/napc/physics/AccelSurv/index.html>.

2 Status of software for Ion Beam Analysis in Materials Development, NAPC/PS/2002/F1.TM - 25886, (IAEA, Vienna 2003).

3 E. Rauhala, N.P. Barradas, S. Fazinić, M. Mayer, E. Szilágyi, M. Thompson, Nucl. Instr. Meth. B244 (2006) 436.

4 Intercomparison of gamma ray analysis packages, IAEA-TECDOC-1011, IAEA, Vienna 1998. Available from:

$<$ http://www-pub.iaea.org/MTCD/publications/PDF/te_1011_prn.pdf $>$.

5 Specialized software utilities for gamma ray spectrometry, IAEA-TECDOC-1275, IAEA, Vienna, 2002. Available from:

$<$ http://www-pub.iaea.org/MTCD/publications/PDF/te_1275_prn.pdf $>$.

6 Intercomparison of PIXE spectrometry software packages, IAEA-TECDOC-1342, IAEA, Vienna, 2003. Available from:

$<$ http://www-pub.iaea.org/MTCD/publications/PDF/te_1342_web.pdf $>$.

7 M. Blaauw, J.L. Campbell, S. Fazinić, M. Jakšić, I. Orlic, P. Van Espen, Nucl. Instr. Meth. B189 (2002) 113.

8 S. Fazinić, M. Jakšić, J.L. Campbell, P. Van Espen, M. Blaauw, I. Orlic, Nucl. Instr. Meth. B183 (2001) 439.

$9 \quad$ E. Szilágyi, F. Pászti, G. Amsel, Nucl. Instr. and Meth. B100 (1995) 103.

10 E. Szilágyi, Nucl. Instr. and Meth. B161-163 (2000) 37.

11 J. Saarilahti and E. Rauhala, Nucl. Instr. and Meth. B64 (1992) 734.

12 E. Rauhala, J. Appl. Phys. 56 (1984) 3324. 
T. Sajavaara, K. Arstila, A. Laakso and J. Keinonen, Nucl. Instr. and Meth. B161-163 (2000) 235. Webb, J. Phys. D: Appl. Phys. 36 (2003) R97. (1998) 1157.

E. Kótai, Nucl. Instr. and Meth. B85 (1994) 588.

L.R. Doolittle, Nucl. Instr. and Meth. B9 (1985) 344.

L.R. Doolittle, Nucl. Instr. and Meth. B15 (1986) 227. Germany (1997).

M. Mayer, AIP Conference Proceedings 475 (1999) 54.

M. Mayer, Nucl. Instr. and Meth. B194 (2002) 177.

N.P. Barradas and A.Vieira, Phys. Rev. E62 (2000) 5818.

C. Jeynes, N.P. Barradas, P.K. Marriott, G. Boudreault, M. Jenkin, E. Wendler and R.P.

E. Kótai, AIP Press Conference Proceedings 392 (1997) 631.

M. Mayer, Technical Report IPP9/113, Max-Planck-Institut für Plasmaphysik, Garching,

P. Børgesen, R. Behrisch and B.M.U. Scherzer, Appl. Phys. A27 (1982) 183.

J.F. Ziegler, R.F. Lever, and J.K. Hirvonen, in Ion Beam Surface Layer Analysis, eds. O. Meyer, G. Linker and F. Käppeler (Plenum, New York, 1976) Vol. 1 p. 163.

www.SRIM.org; J.F. Ziegler, Nucl. Instr. and Meth. B219-220 (2004) 1027. The current version (SRIM2006) has stopping powers indistinguishable from SRIM2003.

J. F. Ziegler, J. P. Biersack, and U. Littmark, Stopping and Ranges of Ions in Solids (Pergamon, New York, 1985). 
N. Bohr, Math. Phys. Medd. Vid. Selsk. 18 (8) (1948).

31

C. Tschalär, Nucl. Instr. Meth. 61 (1968) 141.

32

C. Tschalär, Nucl. Instr. and Meth. 64 (1968) 237.

33

L.C. Feldman, J.W. Mayer, S.T. Picraux, Materials Analysis in Ion Channeling, New York, Academic Press, 1982.

E. Albertazzi, M. Bianconi, G. Lulli, R. Nipoti, M. Cantiano, Nucl. Instrum. Methods Phys. Res. B 118 (1996) 128. (2006) 381-389

A.F. Gurbich, Evaluation and Calculation of Elastic Scattering Cross Sections for Ion Beam Analysis, in: R.C. Haight, M.B. Chadwick, T. Kawano, P. Talou (Eds.) Nuclear Data for Science and Technology, AIP Conf. Proc. vol. 769, Melville, New York, 2005, p. 1670, http://www-nds.iaea.org/sigmacalc/

38 A. F. Gurbich, Nucl. Instr. and Meth. B 129 (1997) 311.

39 A. F. Gurbich, Nucl. Instr. and Meth. B 145 (1998)578.

N.P. Barradas, E. Alves, Nucl. Instrum. Methods Phys. Res. B249 (2006) 796.

41

V. Quillet, F. Abel and M. Schott, Nucl. Instr. and Meth. B 83 (1993) 47.

42

43

44

45

46

Q. Yang, D.J. O’Connor, Zhonglie Wang, Nucl. Instr. and Meth. B61 (1991) 149. 

249 (2006) 823.

$$
\text { B241 (2005) } 316
$$

50 Appl. Phys. 82 (1997) 5958.

55 Methods Phys. Res. B 170 (2000) 1. Nucl. Instr. and Meth. A 248 (1986) 454. B194 (2002) 15. Res. B 136-138 (1998) 159. Nucl. Instrum. Methods Phys. B188 (2002) 120.

60

C. Jeynes, Report on the RBS depth profiling of the IRMM Sb implanted certified standard sample, Internal Report of the University of Surrey Ion Beam Centre, October 2005. 
61

62 1891.

63

64

65

66

67

68

69

70

72 Phys. Res. B 152 (1999) 370.

73

Nipoti, I. Vickridge, D. Walsh, E. Wendler, Nucl. Instrum. Methods Phys. Res. B 161163 (2000) 293. 
Table 1 General information about the participating analysis programs.

\begin{tabular}{|c|c|c|c|c|}
\hline Analysis Program & Technical Contact & Operating Systems & Distribution Mode & Status of source code \\
\hline DEPTH & $\begin{array}{l}\text { Edit Szilágyi } \\
\text { KFKI Research Institute for Particle and Nuclear Physics } \\
\text { Budapest, Hungary } \\
\text { szilagyi@,rmki.kfki.hu; www.kfki.hu/ ionhp/ }\end{array}$ & $\begin{array}{l}\text { DOS (or emulators), } \\
\text { Windows }\end{array}$ & $\begin{array}{l}\text { No charge. Downloadable from the } \\
\text { WEB. }\end{array}$ & $\begin{array}{l}\text { Restricted to author - } \\
\text { not available. }\end{array}$ \\
\hline GISA & $\begin{array}{l}\text { Eero Rauhala } \\
\text { University of Helsinki, Helsinki, Finland } \\
\text { and Jaakko Saarilahti, Technical Research Center of Finland } \\
\text { Eero.rauhala@helsinki.fi; Jaakko.Saarilahti@,vtt.fi }\end{array}$ & DOS (or emulators) & No charge. Write to author for copy. & $\begin{array}{l}\text { Restricted to author - } \\
\text { not available. }\end{array}$ \\
\hline MCERD & $\begin{array}{l}\text { Kai Arstila } \\
\text { University of Helsinki, Helsinki, Finland and IMEC, Leuven, Belgium } \\
\text { Kai.Arstila@iki.fi }\end{array}$ & Linux, UNIX & No charge. Write to author for copy. & $\begin{array}{l}\text { Source code } \\
\text { available. }\end{array}$ \\
\hline $\begin{array}{l}\text { NDF: } \\
\text { DataFurnace }\end{array}$ & $\begin{array}{l}\text { Nuno Barradas } \\
\text { Technological and Nuclear Institute } \\
\text { Sacavem, Portugal } \\
\text { nunoni@itn.pt; www.ee.surrey.ac.uk/ibc/ndf/ }\end{array}$ & Windows, UNIX & $\begin{array}{l}\text { Commercial through Univ. of Surrey } \\
\text { Evaluation copies available by } \\
\text { request. }\end{array}$ & $\begin{array}{l}\text { Restricted to author - } \\
\text { not available. }\end{array}$ \\
\hline $\mathrm{RBX}$ & $\begin{array}{l}\text { Author: Endre Kótai; User in this exercise: Gabor Battistig } \\
\text { KFKI Research Institute for Particle and Nuclear Physics } \\
\text { Budapest, Hungary } \\
\text { kotai@rmki.kfki.hu }\end{array}$ & Windows & No charge. Write to author for copy. & $\begin{array}{l}\text { Restricted to author - } \\
\text { not available. }\end{array}$ \\
\hline RUMP & $\begin{array}{l}\text { Mike Thompson } \\
\text { Dept. of Materials Science, Cornell University } \\
\text { Ithaca, NY USA } \\
\text { mot1@,cornell.edu; www.genplot.com }\end{array}$ & $\begin{array}{l}\text { Windows, Linux, } \\
\text { UNIX, OS } 2\end{array}$ & $\begin{array}{l}\text { Commercial through Computer } \\
\text { Graphics Service } \\
\text { Evaluation copies available on WEB. }\end{array}$ & $\begin{array}{l}\text { Source code } \\
\text { available. }\end{array}$ \\
\hline SIMNRA & $\begin{array}{l}\text { Matej Mayer } \\
\text { MPI for Plasma Physics } \\
\text { Garching, Germany } \\
\text { Matej.Mayer@ipp.mpg.de; www.rzg.mpg.de/ mam/ }\end{array}$ & Windows & $\begin{array}{l}\text { Commercial through MPI for Plasma } \\
\text { Physics } \\
\text { Evaluation copies available on WEB. }\end{array}$ & $\begin{array}{l}\text { Restricted to author - } \\
\text { not available. }\end{array}$ \\
\hline
\end{tabular}


Table 2. Sample structures defined. The following densities were used: $\rho(\mathrm{Si})=4.978 \times 10^{22}$ at $/ \mathrm{cm}^{3}, \rho\left(\mathrm{SiO}_{2}\right)=6.6 \times 10^{22} \mathrm{at} / \mathrm{cm}^{3}, \rho(\mathrm{Au})=5.9 \times 10^{22} \mathrm{at} / \mathrm{cm}^{3}, \rho\left(\mathrm{CD}_{2}\right)=\rho\left(\mathrm{CH}_{2}\right)=1 \times 10^{23} \mathrm{at} / \mathrm{cm}^{3}$, where $\mathrm{D}$ is deuterium. Natural isotopic distribution except where otherwise specified.

\begin{tabular}{|l|l|}
\hline Sample & Structure \\
\hline $\mathrm{S} 1$ & $\mathrm{Si}$ bulk $/ \mathrm{SiO}_{2} 200 \mathrm{~nm} / \mathrm{Au} 50 \mathrm{~nm}$ \\
\hline $\mathrm{S} 2$ & $\mathrm{Si}$ bulk $/ \mathrm{CD}_{2} 150 \mathrm{~nm} / \mathrm{C}^{1} \mathrm{H}_{2} 150 \mathrm{~nm} / \mathrm{CD}_{2} 150 \mathrm{~nm}$ \\
\hline $\mathrm{S} 3$ & $\mathrm{Fe}_{4} \mathrm{~N}$ bulk \\
\hline $\mathrm{S} 4$ & $\mathrm{Si}$ bulk $/ \mathrm{SiO}_{2} 200 \mathrm{~nm} / \mathrm{Au} 20 \mathrm{~nm}$ \\
\hline $\mathrm{S} 5$ & $\begin{array}{l}1 \times 10^{16} \text { at } / \mathrm{cm}^{2} \mathrm{Ge} \text { implant into bulk } \mathrm{Si}: \text { maximum at } 500 \mathrm{~nm}, 100 \mathrm{~nm} \mathrm{FWHM} \\
\text { (Gaussian shape) }\end{array}$ \\
\hline
\end{tabular}


Table 3. Theoretical calculations defined. * denotes a detailed quantitative comparison (see Section 5 and Tables $13,14,15$ ). FWHM is the detector resolution; $\Omega$ is the detector solid angle; bes is the initial beam energy spread in keV; bas is the initial beam angular spread in degrees; $\varnothing$ is the detector diameter in $\mathrm{mm}$. All angles are given in degrees. Entrance and exit angles are given in relation to the normal to the sample, except for ERDA where they are given in respect to the sample surface. The three numbers under the column "pileup" are the beam current in nA, the shaping time ( $\mu \mathrm{s})$ of the amplifier, and the resolution time $(\mu \mathrm{s})$ of the pileup rejection system ( 0 if no pileup rejection system was used). Calculation 1 is the baseline. The stopper foil considered is $6 \mu \mathrm{m}$ Mylar $\left(\mathrm{C}_{10} \mathrm{H}_{8} \mathrm{O}_{4}\right)$ with density $9.6 \times 10^{22}$ at $/ \mathrm{cm}^{3}\left(1.3915 \mathrm{~g} / \mathrm{cm}^{3}\right)$. MS is multiple scattering. PS is plural scattering.

\begin{tabular}{|c|c|c|c|c|c|c|c|c|c|c|c|c|c|c|c|c|c|}
\hline Calculation & Structure & technique & ion & $\begin{array}{l}\mathrm{E} \\
(\mathrm{MeV})\end{array}$ & $\begin{array}{l}\text { FWHM } \\
(\mathrm{keV})\end{array}$ & $\begin{array}{c}\text { straggling, } \\
\text { MS, PS }\end{array}$ & $\begin{array}{l}\Omega \\
(\mathrm{msr})\end{array}$ & $\begin{array}{l}\text { charge } \\
(\mu \mathrm{C})\end{array}$ & pileup & cross section & screening & $\begin{array}{l}\text { stopper } \\
\text { foil }\end{array}$ & $\begin{array}{l}\text { scattering } \\
\text { angle }\end{array}$ & $\begin{array}{l}\text { entrance } \\
\text { angle }\end{array}$ & $\begin{array}{l}\text { exit } \\
\text { angle }\end{array}$ & geometry & bes/bas $/ \varnothing$ \\
\hline $1 *$ & S1 & RBS & ${ }^{4} \mathrm{He}^{+}$ & 1.5 & 16 & Bohr $^{1}$ & 1 & 10 & - & Rutherford & none & no & 150 & 60 & 30 & IBM & ideal \\
\hline 2 & S1 & RBS & ${ }^{4} \mathrm{He}^{+}$ & 1.5 & 16 & Bohr & 1 & 10 & - & Rutherford & Andersen $^{2}$ & no & 150 & 60 & 30 & IBM & ideal \\
\hline 3 & S1 & RBS & ${ }^{4} \mathrm{He}^{+}$ & 1.5 & 16 & Bohr & 1 & 10 & - & Rutherford & L'Ecuyer $^{3}$ & no & 150 & 60 & 30 & IBM & ideal \\
\hline 4 & S1 & RBS & ${ }^{4} \mathrm{He}^{+}$ & 1.5 & 3 & none & 1 & 10 & - & Rutherford & none & no & 150 & 60 & 30 & IBM & ideal \\
\hline 5 & $\mathrm{~S} 1$ & RBS & ${ }^{4} \mathrm{He}^{+}$ & 1.5 & 16 & Bohr & 1 & 10 & - & Rutherford & none & no & 170 & 0 & 10 & Cornell & ideal \\
\hline 6 & S1 & RBS & ${ }^{4} \mathrm{He}^{+}$ & 1.5 & 16 & Bohr & 1 & 10 & - & Rutherford & none & no & 170 & 60 & 60.501 & Cornell & ideal \\
\hline 7 & $\mathrm{~S} 1$ & RBS & ${ }^{4} \mathrm{He}^{+}$ & 1.5 & 16 & Bohr & 1 & 10 & $50 / 5 /$ no & Rutherford & none & no & 150 & 60 & 30 & IBM & ideal \\
\hline 8 & $\mathrm{~S} 1$ & RBS & ${ }^{4} \mathrm{He}^{+}$ & 1.5 & 16 & Bohr & 1 & 10 & $50 / 5 / 0.5$ & Rutherford & none & no & 150 & 60 & 30 & IBM & ideal \\
\hline $9 *$ & S1 & RBS & ${ }^{7} \mathrm{Li}^{+}$ & 3.5 & 16 & Bohr & 1 & 10 & - & Rutherford & none & no & 150 & 60 & 30 & IBM & ideal \\
\hline 10 & S1 & $\begin{array}{l}\text { heavy ion } \\
\text { ERDA }\end{array}$ & ${ }^{127} \mathrm{I}^{10+}$ & 50 & 200 & Bohr & 0.1 & 1000 & - & Rutherford & none & no & 40 & 10 & 30 & IBM & ideal \\
\hline 11 & S1 & $\begin{array}{l}\text { heavy ion } \\
\text { ERDA }\end{array}$ & ${ }^{127} \mathrm{I}^{10+}$ & 50 & $\begin{array}{l}300 \mathrm{ps} \\
50 \mathrm{~cm}\end{array}$ & Bohr & 0.1 & 1000 & - & Rutherford & none & no & 40 & 10 & 30 & IBM & ideal \\
\hline 12 & S1 & $\begin{array}{l}\text { heavy ion } \\
\text { ERDA }\end{array}$ & ${ }^{127} \mathrm{I}^{10+}$ & 50 & 200 & Bohr, MS & 0.1 & 1000 & - & Rutherford & none & no & 40 & 10 & 30 & IBM & ideal \\
\hline 13 & $\mathrm{~S} 1$ & EBS & ${ }^{1} \mathrm{H}^{+}$ & 1.4 & 16 & Bohr & 1 & 10 & - & SigmaCalc $^{4}$ & - & no & 150 & 60 & 30 & IBM & ideal \\
\hline 14 & S1 & EBS & ${ }^{1} \mathrm{H}^{+}$ & 1.8 & 16 & Bohr & 1 & 10 & - & SigmaCalc $^{4}$ & - & no & 150 & 60 & 30 & IBM & ideal \\
\hline 15 & S1 & EBS & ${ }^{4} \mathrm{He}^{+}$ & 3.15 & 16 & none & 1 & 10 & - & SigmaCalc $^{4}$ & - & no & 150 & 60 & 30 & IBM & ideal \\
\hline 16 & S1 & EBS & ${ }^{4} \mathrm{He}^{+}$ & 3.15 & 16 & Bohr & 1 & 10 & - & SigmaCalc $^{4}$ & - & no & 150 & 60 & 30 & IBM & ideal \\
\hline 17 & $\mathrm{~S} 1$ & EBS & ${ }^{4} \mathrm{He}^{+}$ & 3.15 & 16 & Bohr & 1 & 10 & - & SigmaCalc $^{4}$ & - & no & 150 & 60 & 30 & IBM & $1 / 0.05 / 1$ \\
\hline $18 *$ & S2 & ERDA & ${ }^{4} \mathrm{He}^{+}$ & 1.8 & 16 & Bohr & 1 & 10 & - & Rutherford & none & yes & 30 & 15 & 15 & IBM & ideal \\
\hline 19 & S2 & ERDA & ${ }^{4} \mathrm{He}^{+}$ & 1.8 & 16 & Bohr & 1 & 10 & - & Quillet $^{5}$ & - & yes & 30 & 15 & 15 & IBM & ideal \\
\hline 20 & S2 & NRA & ${ }^{3} \mathrm{He}^{+}$ & 1 & 16 & Bohr & 1 & 10 & - & Möller ${ }^{6}$ & - & yes & 170 & 0 & 10 & Cornell & ideal \\
\hline 21 & S3 & NRA & ${ }^{2} \mathrm{H}^{+}$ & 1 & 16 & Bohr & 1 & 10 & - & $1 \mathrm{mb} / \mathrm{sr}$ & - & no & 170 & 0 & 10 & Cornell & ideal \\
\hline 22 & S4 & RBS & ${ }^{4} \mathrm{He}^{+}$ & 1 & 16 & Bohr & 1 & 10 & - & Rutherford & none & no & 150 & 60 & 30 & IBM & $1 / 0.05 / 1$ \\
\hline 23 & S4 & RBS & ${ }^{4} \mathrm{He}^{+}$ & 1 & 16 & Bohr, MS & 1 & 10 & - & Rutherford & none & no & 150 & 60 & 30 & IBM & ideal \\
\hline 24 & S4 & RBS & ${ }^{4} \mathrm{He}^{+}$ & 1 & 16 & $\mathrm{Chu}^{7}, \mathrm{MS}$ & 1 & 10 & - & Rutherford & none & no & 150 & 60 & 30 & IBM & $1 / 0.05 / 1$ \\
\hline 25 & S4 & RBS & ${ }^{4} \mathrm{He}^{+}$ & 1 & 16 & $\begin{array}{l}\text { Chu, MS, } \\
\text { PS }\end{array}$ & 1 & 10 & - & Rutherford & none & no & 170 & 80 & 80.153 & Cornell & $1 / 0.05 / 1$ \\
\hline 26 & S1 & RBS & ${ }^{4} \mathrm{He}^{+}$ & 1 & 16 & $\begin{array}{l}\text { Chu, MS, } \\
\text { PS }\end{array}$ & 1 & 10 & - & Rutherford & none & no & 150 & 60 & 30 & IBM & $1 / 0.05 / 1$ \\
\hline 27 & S5 & RBS & ${ }^{4} \mathrm{He}^{+}$ & 2.7 & 16 & Bohr & 1 & 10 & - & Rutherford & none & no & 150 & 60 & 30 & IBM & ideal \\
\hline 28 & S5 & Channelling & ${ }^{4} \mathrm{He}^{+}$ & 2.7 & 16 & Bohr & 1 & 10 & - & Rutherford & none & no & 150 & 0 & 60 & IBM & ideal \\
\hline
\end{tabular}

${ }^{1}$ Bohr [30]. ${ }^{2}$ Andersen et al. [Fehler! Textmarke nicht definiert.]. ${ }^{3}$ L'Ecuyer et al. [Fehler! Textmarke nicht definiert.]. ${ }^{4}$ Gurbich [37]. ${ }^{5}$ Quillet et al. [41]. ${ }^{6}$ Möller et al. [43]. ${ }^{7}$ Chu [45], Yang et al. [46]. 
Table 4. Calculations reported by each code. Absence of report does not mean that the given code is not capable of doing the given calculation.

\begin{tabular}{|c|c|c|c|c|c|c|c|}
\hline Calculation & DEPTH & GISA & MCERD & NDF & RBX & RUMP & SIMNRA \\
\hline 1 & yes & yes & yes & yes & yes & yes & yes \\
\hline 2 & & & & yes & & yes & yes \\
\hline 3 & yes & & & yes & & & yes \\
\hline 4 & yes & yes & yes & yes & yes & yes & yes \\
\hline 5 & yes & & & yes & & & yes \\
\hline 6 & yes & & & yes & & & yes \\
\hline 7 & & & & yes & & yes & yes \\
\hline 8 & & & & yes & & & yes \\
\hline 9 & yes & yes & yes & yes & yes & yes & yes \\
\hline 10 & yes & & yes & yes & yes & yes & yes \\
\hline 11 & & & yes & & & & yes \\
\hline 12 & yes & & yes & yes & yes & & yes \\
\hline 13 & yes & yes & & yes & yes & yes & yes \\
\hline 14 & yes & yes & & yes & yes & yes & yes \\
\hline 15 & yes & & & yes & yes & yes & yes \\
\hline 16 & yes & & & yes & yes & yes & yes \\
\hline 17 & yes & & & yes & & & yes \\
\hline 18 & yes & & yes & yes & yes & yes & yes \\
\hline 19 & yes & & & yes & yes & yes & yes \\
\hline 20 & & & & yes & & & yes \\
\hline 21 & & & & yes & & & yes \\
\hline 22 & yes & & & yes & & & yes \\
\hline 23 & yes & & & yes & & & yes \\
\hline 24 & yes & & & yes & & & yes \\
\hline 25 & & & & yes & & & yes \\
\hline 26 & & & & yes & & & yes \\
\hline 27 & & & yes & yes & yes & yes & yes \\
\hline 28 & & & & & yes & & \\
\hline
\end{tabular}


Table 5. Experiments defined.

\begin{tabular}{|c|c|c|c|}
\hline Experiment & nominal structure & analysing ion & purpose \\
\hline$\overline{E 1}$ & $\mathrm{a}-\mathrm{Si} / \mathrm{SiO}_{2} 13 \times 10^{15}$ at. $/ \mathrm{cm}^{2} / \mathrm{C} 4 \times 10^{15}$ at. $/ \mathrm{cm}^{2}$ & $2 \mathrm{MeV}^{4} \mathrm{He}^{+}$ & $\begin{array}{l}\text { Sanity check - reproduction of a } \mathrm{Si} \\
\text { spectrum }\end{array}$ \\
\hline E2 & $\begin{array}{l}4.81(3) \times 10^{16} / \mathrm{cm}^{2} 80 \mathrm{keV} \mathrm{Sb} \text { implant in } \\
\mathrm{Si} \text { bulk } / \mathrm{SiO}_{2} 90 \mathrm{~nm}\end{array}$ & $\begin{array}{ll}1.557 & \mathrm{MeV} \\
{ }^{4} \mathrm{He}^{+} & \end{array}$ & Retrieval of Sb fluence \\
\hline E3 & Si bulk / Hafnium oxide with impurities & $2.5 \mathrm{MeV}^{4} \mathrm{He}^{+}$ & Determination of structure \\
\hline E4 & Si bulk $/ \operatorname{Re} 5 \mathrm{~nm} /(\operatorname{Co} 2 \mathrm{~nm} / \operatorname{Re} 0.5 \mathrm{~nm})_{16}$ & $1 \mathrm{MeV}^{4} \mathrm{He}^{+}$ & $\begin{array}{l}\text { Determination of complex structure } \\
\text { and roughness at grazing angle }\end{array}$ \\
\hline
\end{tabular}


Table 6. Analyses of experimental data reported by each code. Absence of report does not mean that the given code is not capable of doing the given calculation. DEPTH is not a code designed for analysis of experimental data. MCERD did not participate in this phase of the intercomparison exercise.

\begin{tabular}{l|lllllll}
\hline Experiment & DEPTH & GISA & MCERD & NDF & RBX & RUMP & SIMNRA \\
\hline E1 & yes & yes & & yes & & yes & yes \\
E2 & & yes & yes & yes & yes & yes \\
E3 & & yes & yes & & yes & yes \\
E4 & & & & yes & & & yes \\
\hline
\end{tabular}


Table 7. Parameters used for the analysis of experiment E1 (amorphous Si).

\begin{tabular}{|c|c|c|c|c|c|c|c|}
\hline Code & Si Stopping & pile-up & $\begin{array}{l}\text { beam fluence } \\
(\mu \mathrm{C}) \text { (nominal 46) }\end{array}$ & $\begin{array}{l}\text { beam energy and energy } \\
\text { calibration }\end{array}$ & $\begin{array}{l}\text { FWHM } \\
(\mathrm{keV})\end{array}$ & geometry & layer structure \\
\hline DEPTH & SRIM95 & no & 47.0 & nominal & nominal & nominal & nominal \\
\hline GISA & $0.97 \times$ SRIM91 & no & nominal & nominal & nominal & nominal & nominal \\
\hline NDF & Barradas $^{1}$ & yes & nominal & nominal & nominal & nominal & nominal \\
\hline RUMP & SRIM03 & yes & 46.74 & nominal & nominal & nominal & nominal \\
\hline SIMNRA & SRIM03 & yes & nominal & nominal & nominal & nominal & nominal \\
\hline
\end{tabular}

${ }^{1}$ Barradas et al. [57]. 
Table 8 . Normalised $\chi^{2}$ values obtained for different energy windows of experiment E1 (amorphous $\mathrm{Si}$ ).

\begin{tabular}{l|lll}
\hline Code & Si high energy & Si signal & pile-up \\
& $800-1100 \mathrm{keV}$ & $250-1150 \mathrm{keV}$ & $1250-1900 \mathrm{keV}$ \\
\hline DEPTH & 1.303 & 1.384 & 5.953 \\
GISA & 1.034 & 1.583 & 5.953 \\
NDF & 1.018 & 5.695 & 1.374 \\
RUMP & 1.064 & 2.043 & 1.816 \\
SIMNRA & 1.000 & 6.254 & 1.389 \\
\hline
\end{tabular}


Table 9. Results obtained for experiment E2 (certified Sb implant). Only the Sb fluence was required to be derived in the analysis. The certified value is $48.1(3) \times 10^{15} \mathrm{Sb} / \mathrm{cm}^{2}$. The mean value of all codes is $47.99(7) \times 10^{15} \mathrm{Sb} / \mathrm{cm}^{2}$. The last three columns are for information only: these parameters are not involved in the fluence determination. The depth resolution at Rp is $1.5 \times 10^{17} \mathrm{at} . / \mathrm{cm}^{2}$.

\begin{tabular}{|c|c|c|c|c|c|c|c|}
\hline Code & Stopping & $\begin{array}{l}\text { Sb fluence } \\
\left(10^{15} \text { at. } / \mathrm{cm}^{2}\right)\end{array}$ & $\begin{array}{l}\text { Sb deviation } \\
\text { from certified } \\
\text { value }(\%)\end{array}$ & $\begin{array}{l}\text { Ratio } \mathrm{A} / \mathrm{B} \text { of } \mathrm{Sb} \\
\text { content for two } \\
\text { detectors }\end{array}$ & $\begin{array}{l}\text { Sb peak } \\
\text { depth } R_{p} \\
\left(10^{17} \text { at. } / \mathrm{cm}^{2}\right)\end{array}$ & $\begin{array}{l}\text { Sb peak } \\
\text { width } \Gamma \\
\left(10^{17} \text { at. } / \mathrm{cm}^{2}\right)\end{array}$ & $\begin{array}{l}\text { Oxide thickness } \\
\mathrm{t}_{\mathrm{SiO} 2} \\
\left(10^{17} \text { at. } / \mathrm{cm}^{2}\right)\end{array}$ \\
\hline GISA & $0.96 \times$ SRIM91 & 47.9 & -0.41 & & 9.8 & 6.7 & 6.0 \\
\hline RBX & SRIM03 & 48.0 & -0.21 & & 9.3 & 6.2 & 5.8 \\
\hline RUMP & SRIM03 & 48.08 & -0.04 & 1.00417 & 9.6 & 6.0 & 6.1 \\
\hline SIMNRA & SRIM03 & 47.95 & -0.31 & 1.00476 & - & - & 6.0 \\
\hline
\end{tabular}


Table 10. Results obtained for experiment E3 (hafnium oxide on silicon). Layer thickness $\mathrm{t}$ and elemental total amounts are in $10^{15} / \mathrm{cm}^{2}$ units, elemental concentrations in at.\%.

\begin{tabular}{|c|c|c|c|c|}
\hline & GISA & $\mathrm{NDF}$ & RUMP & SIMNRA \\
\hline $\begin{array}{l}\text { surface layer } \\
\text { main layer }\end{array}$ & $\overline{\mathrm{t}}=898 ;$ Hf 33.5 O $66.2 \mathrm{Zr} 0.34$ & $\overline{\mathrm{t}}=882 ;$ Hf 33.5 O $66.1 \mathrm{Zr} 0.34$ & $\overline{\mathrm{t}}=831 ; \mathrm{Hf} 35.0 \mathrm{O} 64.7 \mathrm{Zr} 0.35$ & $\begin{array}{l}\mathrm{t}=80 ; \mathrm{H} 1 \mathrm{O} 1 \mathrm{C} 1 \\
\mathrm{t}=870 ; \mathrm{Hf} 34.0 \text { O } 65.7 \mathrm{Zr} 0.33 \\
\text { roughness FWHM } 93 \times 10^{15} / \mathrm{cm}^{2}\end{array}$ \\
\hline interfacial layer & - & $\mathrm{t}=32 ; \mathrm{Si} 1 \mathrm{O} 2$ & - & - \\
\hline substrate & $\mathrm{Si}$ & $\mathrm{Si}$ & $\mathrm{Si}$ & Si $99.92 \mathrm{Hf} 0.078$ \\
\hline Hf total amount & 300.8 & 295.5 & 290.7 & 295.8 \\
\hline O total amount & 594.5 & 604.3 & 537.4 & 598.3 \\
\hline $\mathrm{Zr}$ total amount & 3.05 & 3.00 & 2.91 & 2.87 \\
\hline stopping power & SRIM91 & Barradas, SRIM03 ${ }^{1-}$ & SRIM03 & SRIM03 \\
\hline scattering cross sections & O: SigmaCalc & O: SigmaCalc & O: Cameron $^{2}$ & O: SigmaCalc \\
\hline 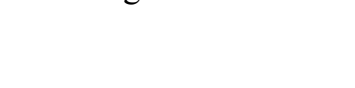 & no screening & Andersen screening & Andersen screening & $\begin{array}{l}\text { C: Feng et. al }{ }^{3} \\
\text { Andersen screening }\end{array}$ \\
\hline plural scattering & $\begin{array}{l}\text { ad-hoc contribution required to } \\
\text { simulate the background below } \\
\text { the } O \text { signal }\end{array}$ & $\begin{array}{l}\text { double scattering calculated; ad-hoc } \\
\text { contribution required to simulate the } \\
\text { background below the Hf signal }\end{array}$ & $\begin{array}{l}\text { ad-hoc contribution required to } \\
\text { simulate the background below the } \\
\text { Hf signal }\end{array}$ & $\begin{array}{l}\text { Hf in substrate to simulate plural } \\
\text { scattering }\end{array}$ \\
\hline pile-up & no & yes & yes & yes \\
\hline
\end{tabular}

\footnotetext{
The stopping of Si was that in Barradas et al. [57], all other were SRIM03.

2 Cameron 64
}

${ }^{3}$ Feng et al. ${ }^{65}$ 
Table 11. Layer structure obtained for experiment E4 (Co/Re multilayer).

\begin{tabular}{|c|c|c|}
\hline layer & $\begin{array}{c}\text { t }_{\text {SIMNRA }} \\
\left(10^{15} \mathrm{at} . / \mathrm{cm}^{2}\right)\end{array}$ & $\begin{array}{c}\mathrm{t}_{\mathrm{NDF}} \\
\left(10^{15} \text { at. } / \mathrm{cm}^{2}\right)\end{array}$ \\
\hline $1-\mathrm{C}$ ( surface) & $41.2^{1}$ & 50.7 \\
\hline $2-\mathrm{Re}$ & 4.2 & 4.0 \\
\hline $3-\mathrm{Co}$ & 24 & 22.2 \\
\hline $4-\mathrm{Re}$ & 3.75 & 3.7 \\
\hline $5-\mathrm{Co}$ & 23.5 & 22.7 \\
\hline $6-\mathrm{Re}$ & 3.6 & 3.4 \\
\hline $7-\mathrm{Co}$ & 24 & 20.9 \\
\hline $8-\mathrm{Re}$ & 3.65 & 3.3 \\
\hline $9-\mathrm{Co}$ & 22 & 19.1 \\
\hline $10-\mathrm{Re}$ & 4 & 3.6 \\
\hline $11-\mathrm{Co}$ & 21 & 17.6 \\
\hline $12-\mathrm{Re}$ & 3.3 & 3.1 \\
\hline $13-\mathrm{Co}$ & 21 & 19.9 \\
\hline $14-\operatorname{Re}$ & 3.8 & 3.8 \\
\hline $15-\mathrm{Co}$ & 24 & 22.5 \\
\hline $16-\mathrm{Re}$ & 3.2 & 3.8 \\
\hline 17 - Co & 21.5 & 21.3 \\
\hline $18-\operatorname{Re}$ & 3.6 & 3.3 \\
\hline 19 - Co & 23 & 19.8 \\
\hline $20-\operatorname{Re}$ & 3.3 & 3.4 \\
\hline $21-\mathrm{Co}$ & 19 & 19.8 \\
\hline $22-\operatorname{Re}$ & 3.3 & 3.2 \\
\hline 23 - Co & 19 & 19.6 \\
\hline $24-\mathrm{Re}$ & 3 & 4.0 \\
\hline $25-\mathrm{Co}$ & 19 & 23.5 \\
\hline $26-\operatorname{Re}$ & 2.5 & 2.0 \\
\hline $27-\mathrm{Co}$ & 18 & 18.2 \\
\hline $28-\operatorname{Re}$ & 2.5 & 2.4 \\
\hline $29-\mathrm{Co}$ & 18 & 18.1 \\
\hline $30-\mathrm{Re}$ & 2.5 & 2.7 \\
\hline $31-\mathrm{Co}$ & 18 & 19.6 \\
\hline $32-\mathrm{Re}$ & 26.5 & 24.0 \\
\hline 33 - Si substrate & infinite & infinite \\
\hline
\end{tabular}


Table 12. Quantitative analysis of differences amongst simulations in Calculation 1 (standard RBS). Only codes that used SRIM03 stopping are included. The columns for each code give the deviation, in $\%$ or in $\mathrm{keV}$, relative to the average value. The average and standard deviation values were calculated, for the yield and height values, from the DEPTH, NDF, RBX, RUMP, and SIMNRA values. MCERD was excluded because the statistical variation of yield leads to fluctuations that can disturb the average. For the edge position and width, the RBX value was also excluded from the calculation of the average and standard deviation, due to differences in the straggling calculation.

\begin{tabular}{|c|c|c|c|c|c|c|c|}
\hline signal & DEPTH & MCERD & NDF & RBX & RUMP & SIMNRA & average \\
\hline Au yield (\%) & -0.11 & -0.01 & -0.01 & -0.19 & +0.25 & +0.06 & 637885 counts $\pm 0.17 \%$ \\
\hline Au height $(\%)$ & -0.17 & -0.18 & -0.01 & +0.18 & +0.07 & -0.07 & 5901.4 counts $/ \mathrm{keV} \pm 0.13 \%$ \\
\hline $1340-1360 \mathrm{keV}$ & & & & & & & \\
\hline $\mathrm{Si}$ in $\mathrm{SiO} 2$ height $(\%)$ & +0.09 & -0.36 & -0.09 & +0.16 & -0.05 & -0.12 & 222.54 counts $/ \mathrm{keV} \pm 0.12 \%$ \\
\hline $720-740 \mathrm{keV}$ & & & & & & & \\
\hline Si substrate height $(\%)$ & +0.16 & +0.10 & -0.16 & +0.06 & +0.15 & -0.21 & 624.2 counts $/ \mathrm{keV} \pm 0.17 \%$ \\
\hline $580-600 \mathrm{keV}$ & & & & & & & \\
\hline $\mathrm{O}$ in $\mathrm{SiO} 2$ height $(\%)$ & +0.29 & +0.70 & -0.19 & +0.28 & -0.22 & -0.16 & 906.8 counts $/ \mathrm{keV} \pm 0.26 \%$ \\
\hline Au right edge position (keV) & -0.1 & -0.2 & -0.0 & -0.1 & +0.1 & +0.1 & $1392.1 \pm 0.1 \mathrm{keV}$ \\
\hline $\mathrm{Au}$ left edge position (keV) & +0.1 & -0.3 & +0.1 & +0.4 & -0.0 & -0.1 & $1284.9 \pm 0.1 \mathrm{keV}$ \\
\hline Si surface edge position (keV) & +1.0 & -0.7 & -0.3 & +0.3 & -0.3 & -0.4 & $795.0 \pm 0.7 \mathrm{keV}$ \\
\hline $\mathrm{SiO} 2 / \mathrm{Si}$ edge position $(\mathrm{keV})$ & +0.8 & -0.1 & -0.2 & +1.1 & -0.2 & -0.3 & $648.0 \pm 0.5 \mathrm{keV}$ \\
\hline $\mathrm{O}$ right edge position $(\mathrm{keV})$ & +1.0 & -0.7 & -0.3 & +0.3 & -0.3 & -0.3 & $512.7 \pm 0.7 \mathrm{keV}$ \\
\hline O left edge position (keV) & +0.6 & -2.8 & -0.3 & -0.2 & -0.2 & -0.2 & $393.5 \pm 0.4 \mathrm{keV}$ \\
\hline Au right edge width (keV) & -0.1 & +2.2 & +0.4 & +0.1 & -0.2 & -0.1 & $14.4 \pm 0.3 \mathrm{keV}$ \\
\hline Si surface edge width $(\mathrm{keV})$ & -0.2 & +0.2 & -0.2 & -3.7 & +0.8 & -0.5 & $18.9 \pm 0.6 \mathrm{keV}$ \\
\hline $\mathrm{SiO} 2 / \mathrm{Si}$ edge width (keV) & +0.4 & +1.9 & -0.5 & -4.7 & +1.0 & -0.8 & $23.2 \pm 0.8 \mathrm{keV}$ \\
\hline $\mathrm{O}$ right edge width (keV) & -1.9 & -1.5 & +0.3 & -3.6 & +1.7 & -0.2 & $20.1 \pm 1.5 \mathrm{keV}$ \\
\hline O left edge width (keV) & +2.5 & +3.5 & -1.2 & -3.7 & -0.1 & -1.2 & $18.3 \pm 1.7 \mathrm{keV}$ \\
\hline
\end{tabular}


Table 13. Quantitative analysis of differences amongst simulations in Calculation 9 (heavy ion RBS). Only codes that used SRIM03 stopping are included. The columns for each code give the deviation, in $\%$ or in $\mathrm{keV}$, relative to the average value. The average and standard deviation values were calculated, for the yield and height values, from the DEPTH, NDF, RBX, RUMP, and SIMNRA values. MCERD was excluded because the statistical variation of yield leads to fluctuations that can disturb the average. For the edge position and width, the RBX value was also excluded from the calculation of the average and standard deviation, due to differences in the straggling calculation.

\begin{tabular}{|c|c|c|c|c|c|c|c|}
\hline signal & DEPTH & MCERD & $\mathrm{NDF}$ & RBX & RUMP & SIMNRA & average \\
\hline Au yield (\%) & +0.4 & -0.1 & +0.1 & -1.3 & +0.5 & +0.2 & 260191 counts $\pm 0.7 \%$ \\
\hline Au height $(\%)$ & +0.2 & -0.2 & +0.2 & -1.1 & +0.5 & +0.2 & 1360.7 counts $/ \mathrm{keV} \pm 0.6 \%$ \\
\hline $2950-3000 \mathrm{keV}$ & & & & & & & \\
\hline $\mathrm{Si}$ in $\mathrm{SiO} 2$ height $(\%)$ & +0.6 & -2.6 & -0.1 & +0.1 & +0.1 & -0.2 & 61.45 counts $/ \mathrm{keV} \pm 0.4 \%$ \\
\hline $1120-1170 \mathrm{keV}$ & & & & & & & \\
\hline Si substrate height $(\%)$ & +0.3 & -0.3 & -0.2 & -0.0 & +0.1 & -0.2 & 173.45 counts $/ \mathrm{keV} \pm 0.18 \%$ \\
\hline $900-950 \mathrm{keV}$ & & & & & & & \\
\hline $\mathrm{O}$ in $\mathrm{SiO} 2$ height $(\%)$ & +0.3 & +1.7 & -0.4 & +0.1 & +0.2 & -0.3 & 346.70 counts $/ \mathrm{keV} \pm 0.32 \%$ \\
\hline $450-500 \mathrm{keV}$ & & & & & & & \\
\hline Au right edge position $(\mathrm{keV})$ & +0.1 & -0.3 & -0.0 & -0.0 & -0.0 & -0.0 & $3068.0 \pm 0.1 \mathrm{keV}$ \\
\hline Au left edge position $(\mathrm{keV})$ & +0.6 & -0.4 & -0.1 & +0.7 & -0.1 & -0.2 & $2877.1 \pm 0.4 \mathrm{keV}$ \\
\hline Si surface edge position $(\mathrm{keV})$ & +2.8 & +0.7 & -1.1 & +2.3 & -0.9 & -1.0 & $1233.6 \pm 1.9 \mathrm{keV}$ \\
\hline $\mathrm{SiO} 2 / \mathrm{Si}$ edge position $(\mathrm{keV})$ & +2.6 & +0.9 & -1.2 & -9.5 & -0.7 & -0.8 & $1036.4 \pm 1.8 \mathrm{keV}$ \\
\hline $\mathrm{O}$ right edge position $(\mathrm{keV})$ & +3.3 & +0.0 & -1.3 & +1.4 & -1.1 & -0.9 & $537.9 \pm 2.2 \mathrm{keV}$ \\
\hline O left edge position (keV) & +2.0 & +0.2 & -1.1 & -6.4 & -0.4 & -0.4 & $416.1 \pm 1.4 \mathrm{keV}$ \\
\hline Au right edge width (keV) & -0.1 & -0.2 & +0.8 & -0.7 & -0.0 & -0.6 & $17.2 \pm 0.6 \mathrm{keV}$ \\
\hline Au left edge width $(\mathrm{keV})$ & -0.0 & -1.8 & +0.0 & -5.9 & +0.5 & -0.5 & $29.6 \pm 0.4 \mathrm{keV}$ \\
\hline Si surface edge width $(\mathrm{keV})$ & -0.8 & -1.4 & -0.2 & -3.5 & +4.1 & -0.4 & $20.8 \pm 3.1 \mathrm{keV}$ \\
\hline $\mathrm{SiO} 2 / \mathrm{Si}$ edge width $(\mathrm{keV})$ & -1.8 & -1.1 & -1.0 & -4.5 & +4.4 & -1.5 & $26.9 \pm 3.0 \mathrm{keV}$ \\
\hline $\mathrm{O}$ right edge width $(\mathrm{keV})$ & -1.8 & +10.0 & +1.4 & -5.4 & +1.1 & -0.6 & $23.6 \pm 1.5 \mathrm{keV}$ \\
\hline O left edge width $(\mathrm{keV})$ & -0.8 & +3.7 & -0.2 & -9.6 & +1.2 & -0.1 & $29.7 \pm 0.9 \mathrm{keV}$ \\
\hline
\end{tabular}


Table 14. Quantitative analysis of differences amongst simulations in Calculation 18 (ERDA). Only codes that used SRIM03 stopping are included. The columns for each code give the deviation, in $\%$ or in $\mathrm{keV}$, relative to the average value. The average and standard deviation values were calculated, for the yield and values, from the DEPTH, NDF, RBX, RUMP, and SIMNRA values. MCERD was excluded because the statistical variation of yield leads to fluctuations that can disturb the average. For the edge position and width, the RBX and RUMP values were also excluded from the calculation of the average and standard deviation, due to differences in the straggling calculation.

\begin{tabular}{|c|c|c|c|c|c|c|c|}
\hline signal & DEPTH & MCERD & NDF & RBX & RUMP & SIMNRA & average \\
\hline${ }^{2} \mathrm{H}$ high yield (\%) & +0.8 & +1.3 & -0.4 & +0.3 & -0.3 & -0.4 & 22391 counts $\pm 0.5 \%$ \\
\hline${ }^{2} \mathrm{H}$ low yield $(\%)$ & +1.2 & +0.8 & -0.6 & +0.2 & -0.2 & -0.6 & 27884 counts $/ \mathrm{keV} \pm 0.7 \%$ \\
\hline${ }^{1} \mathrm{H}$ yield $(\%)$ & +2.2 & -0.5 & -0.7 & +0.0 & -0.7 & -0.8 & 69339 counts $/ \mathrm{keV} \pm 1.3 \%$ \\
\hline${ }^{2} \mathrm{H}$ high right edge position (keV) & -2.1 & +0.8 & +1.2 & +1.3 & +0.2 & +0.8 & $904.5 \pm 1.8 \mathrm{keV}$ \\
\hline${ }^{2} \mathrm{H}$ high left edge position $(\mathrm{keV})$ & -1.5 & +0.9 & +0.8 & +2.0 & +1.4 & +0.7 & $809.9 \pm 1.2 \mathrm{keV}$ \\
\hline${ }^{2} \mathrm{H}$ low edge position (keV) & -1.0 & +1.1 & +0.4 & +2.8 & -0.4 & +0.6 & $708.5 \pm 0.9 \mathrm{keV}$ \\
\hline${ }^{2} \mathrm{H}$ low edge position $(\mathrm{keV})$ & -1.0 & +0.4 & +0.6 & +3.9 & -2.7 & +0.4 & $597.7 \pm 0.9 \mathrm{keV}$ \\
\hline${ }^{1} \mathrm{H}$ yield edge position $(\mathrm{keV})$ & -2.4 & +1.3 & +1.1 & +0.4 & +4.5 & +1.3 & $556.6 \pm 2.1 \mathrm{keV}$ \\
\hline${ }^{1} \mathrm{H}$ yield edge position $(\mathrm{keV})$ & -2.2 & +1.4 & +1.1 & +1.0 & +4.4 & +1.1 & $478.8 \pm 1.9 \mathrm{keV}$ \\
\hline${ }^{2} \mathrm{H}$ high right edge width (keV) & +1.1 & -1.0 & -0.5 & -2.1 & -9.2 & -0.7 & $23.9 \pm 1.0 \mathrm{keV}$ \\
\hline${ }^{2} \mathrm{H}$ high left edge width $(\mathrm{keV})$ & +1.3 & -1.1 & -0.6 & -2.6 & -7.6 & -0.6 & $25.2 \pm 1.1 \mathrm{keV}$ \\
\hline${ }^{2} \mathrm{H}$ low edge width $(\mathrm{keV})$ & +1.3 & -2.3 & -0.2 & -3.4 & -7.3 & -1.0 & $27.8 \pm 1.1 \mathrm{keV}$ \\
\hline${ }^{2} \mathrm{H}$ low edge width $(\mathrm{keV})$ & +2.1 & -0.8 & -1.1 & -4.8 & -7.4 & -1.0 & $30.4 \pm 1.8 \mathrm{keV}$ \\
\hline${ }^{1} \mathrm{H}$ yield edge width (keV) & +1.5 & -1.5 & -0.6 & -3.0 & -8.5 & -0.9 & $25.8 \pm 1.3 \mathrm{keV}$ \\
\hline${ }^{1} \mathrm{H}$ yield edge width (keV) & +2.2 & -1.4 & +0.2 & -3.0 & -6.8 & -2.3 & $26.6 \pm 2.3 \mathrm{keV}$ \\
\hline
\end{tabular}




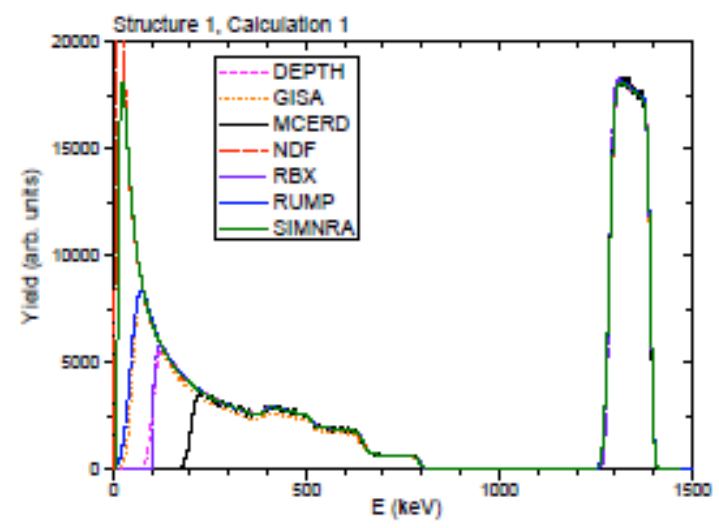

Figure 1. Calculation 1 - simple RBS spectrum from Si bulk / $\mathrm{SiO}_{2} 200 \mathrm{~nm} / \mathrm{Au} 50 \mathrm{~nm} .1 .5 \mathrm{MeV}^{4} \mathrm{He}^{+}$, $\theta_{\text {scatt }}=150^{\circ}, \alpha_{\text {inc }}=60^{\circ}$, IBM geometry, $16 \mathrm{keV} \mathrm{FWHM,} \mathrm{Bohr} \mathrm{straggling,} \mathrm{ideal} \mathrm{beam} \mathrm{and} \mathrm{detector.} \mathrm{No}$ screening.

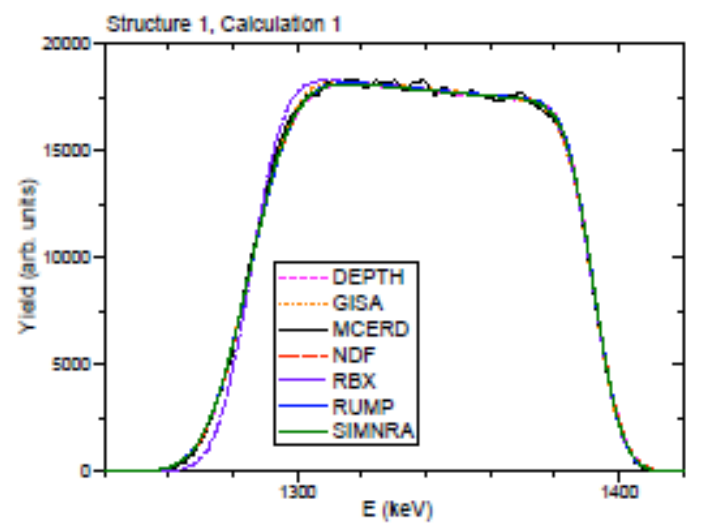

Figure 2. High energy region of Calculation 1 - simple RBS spectrum. 


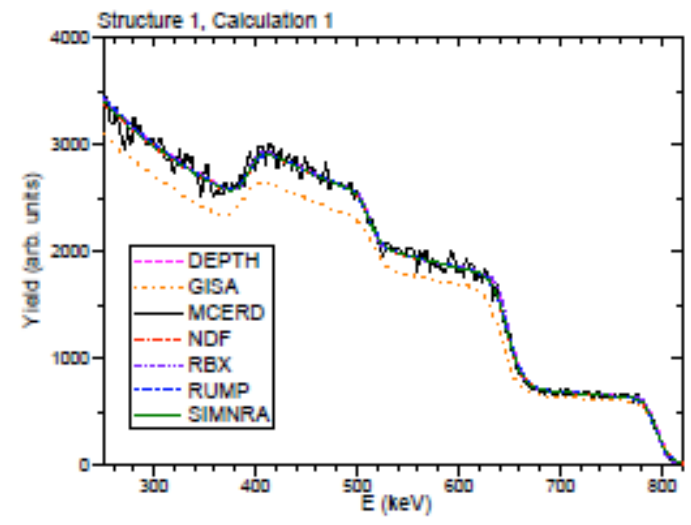

Figure 3. Low energy region of Calculation 1 - simple RBS spectrum.

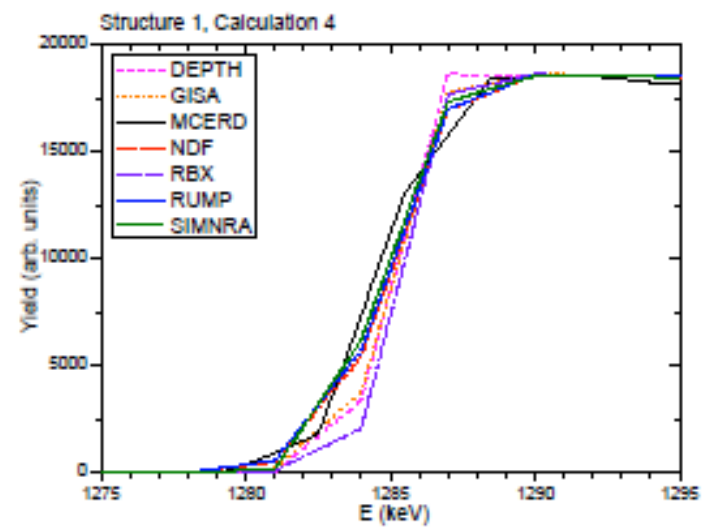

Figure 4. Calculation 4 - simple RBS spectrum from $\mathrm{Si}$ bulk / $\mathrm{SiO}_{2} 200 \mathrm{~nm} / \mathrm{Au} 50 \mathrm{~nm} .1 .5 \mathrm{MeV}{ }^{4} \mathrm{He}^{+}$, $\theta_{\text {scatt }}=150^{\circ}, \alpha_{\text {inc }}=60^{\circ}$, IBM geometry, $3 \mathrm{keV} \mathrm{FWHM,} \mathrm{no} \mathrm{straggling,} \mathrm{ideal} \mathrm{beam} \mathrm{and} \mathrm{detector.} \mathrm{No} \mathrm{screening.}$ 


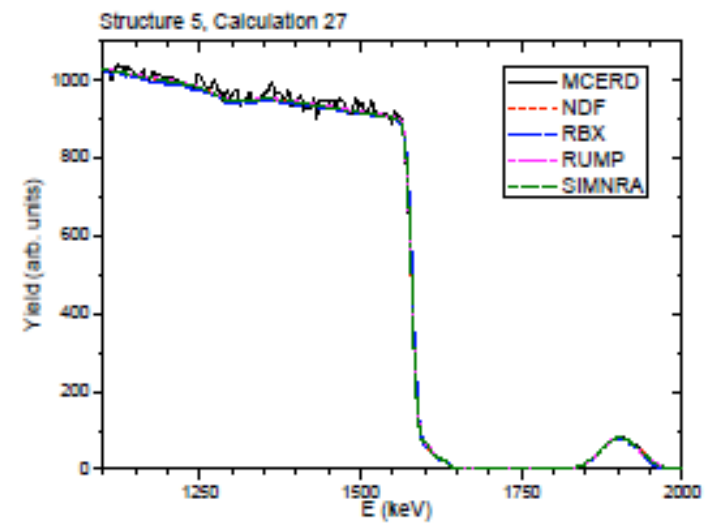

Figure 5. Calculation 27 - continuous profile RBS spectrum from $1 \times 10^{16} \mathrm{at} / \mathrm{cm}^{2} \mathrm{Ge}$ implant into bulk Si. 2.7 $\mathrm{MeV}^{4} \mathrm{He}^{+}, \theta_{\text {scatt }}=150^{\circ}, \alpha_{\text {inc }}=60^{\circ}$, IBM geometry, $16 \mathrm{keV} \mathrm{FWHM,} \mathrm{Bohr} \mathrm{straggling,} \mathrm{ideal} \mathrm{beam} \mathrm{and}$ detector. No screening.

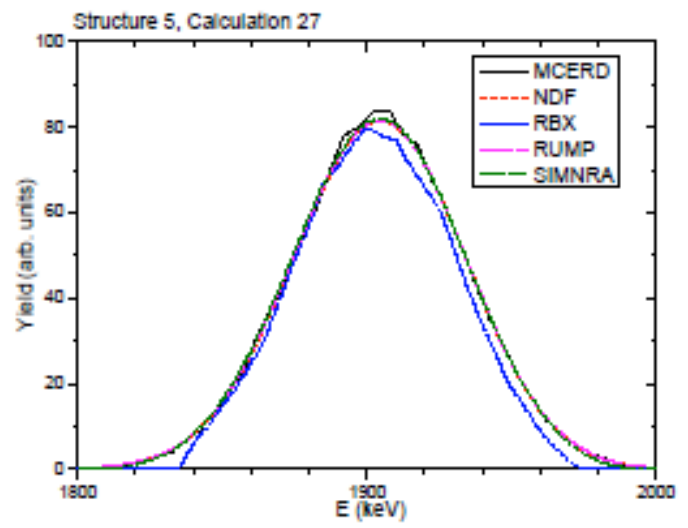

Figure 6. Calculation 27 - Ge peak. 


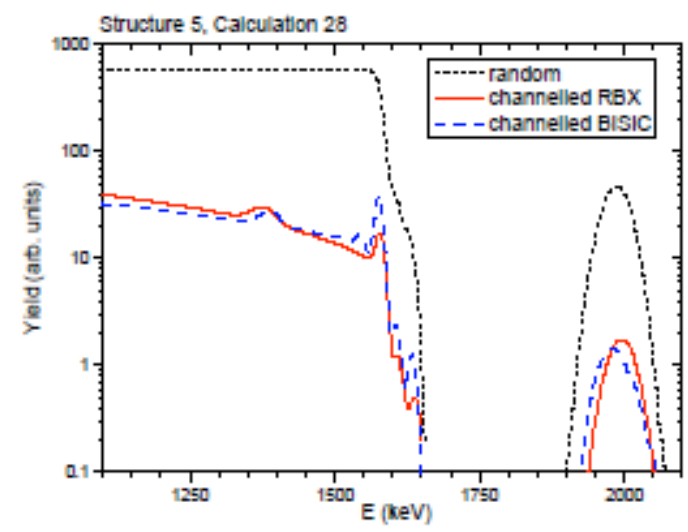

Figure 7. Calculation 28 - RBS/Channelling spectrum from $1 \times 10^{16}$ at $/ \mathrm{cm}^{2}$ Ge implant into bulk (100)Si. The Ge is $100 \%$ substitional, the $\mathrm{Si}$ has a point defect distribution that follows the Ge but with a $2 \%$ maximum concentration. $2.7 \mathrm{MeV}{ }^{4} \mathrm{He}^{+}, \theta_{\text {scatt }}=150^{\circ}, \alpha_{\text {inc }}=60^{\circ}$, IBM geometry, $16 \mathrm{keV} \mathrm{FWHM,} \mathrm{Bohr}$ straggling, ideal beam and detector. No screening.

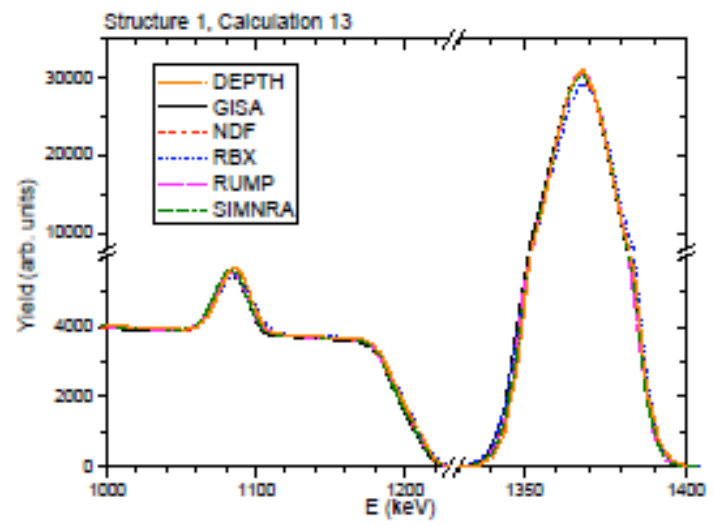

Figure 8. Calculation 13 - Elastic backscattering without resonances, from Si bulk / $\mathrm{SiO}_{2} 200 \mathrm{~nm} / \mathrm{Au} 50$ nm. $1.4 \mathrm{MeV}^{1} \mathrm{H}^{+}, \theta_{\text {scatt }}=150^{\circ}, \alpha_{\mathrm{inc}}=60^{\circ}$, IBM geometry, $16 \mathrm{keV} \mathrm{FWHM,} \mathrm{Bohr} \mathrm{straggling,} \mathrm{ideal} \mathrm{beam} \mathrm{and}$ detector. No screening. 


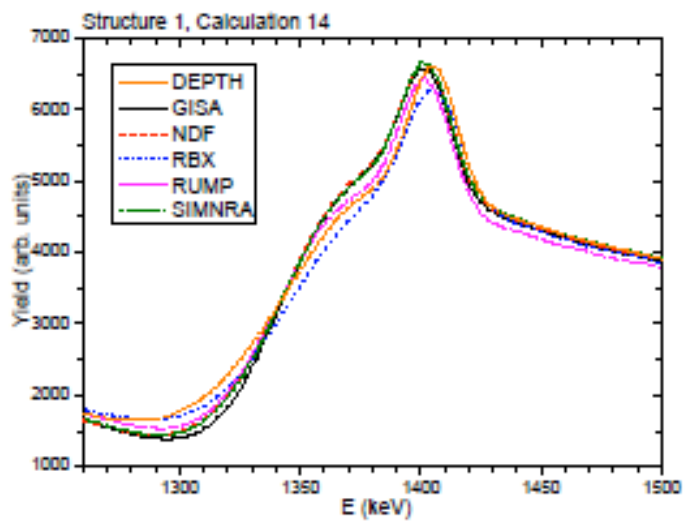

Figure 9. Calculation 14 - Elastic backscattering with resonances, from Si bulk / $\mathrm{SiO}_{2} 200 \mathrm{~nm} / \mathrm{Au} 50 \mathrm{~nm}$. $1.8 \mathrm{MeV}^{1} \mathrm{H}^{+}, \theta_{\text {scatt }}=150^{\circ}, \alpha_{\text {inc }}=60^{\circ}$, IBM geometry, $16 \mathrm{keV} \mathrm{FWHM,} \mathrm{Bohr} \mathrm{straggling,} \mathrm{ideal} \mathrm{beam} \mathrm{and}$ detector. No screening.

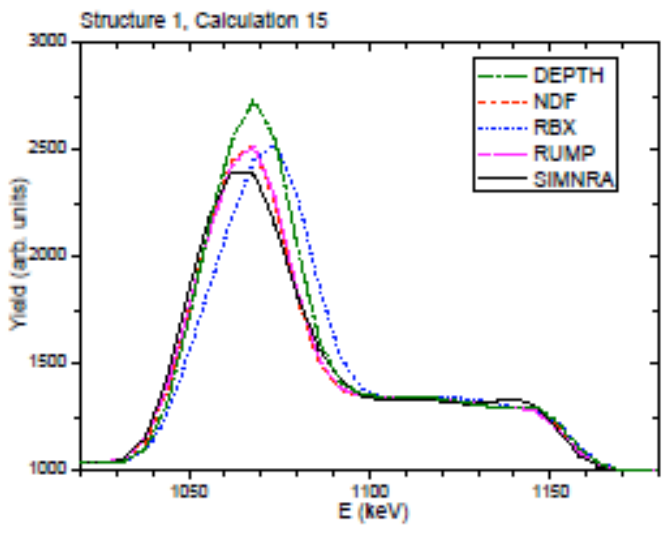

Figure 10. Calculation 15 - Elastic backscattering with sharp resonances and without straggling, from Si bulk / $\mathrm{SiO}_{2} 200 \mathrm{~nm} / \mathrm{Au} 50 \mathrm{~nm} .3 .15 \mathrm{MeV}^{4} \mathrm{He}^{+}, \theta_{\text {scatt }}=150^{\circ}, \alpha_{\text {inc }}=60^{\circ}$, IBM geometry, $16 \mathrm{keV} \mathrm{FWHM,} \mathrm{no}$ straggling, ideal beam and detector. No screening. 


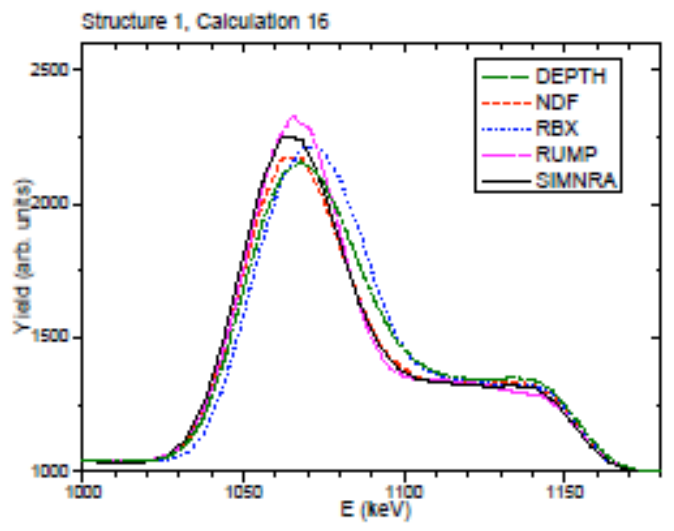

Figure 11. Calculation 16 - Elastic backscattering with sharp resonances and with straggling, from Si bulk / $\mathrm{SiO}_{2} 200 \mathrm{~nm} / \mathrm{Au} 50 \mathrm{~nm} .3 .15 \mathrm{MeV}^{4} \mathrm{He}^{+}, \theta_{\text {scatt }}=150^{\circ}, \alpha_{\text {inc }}=60^{\circ}$, IBM geometry, $16 \mathrm{keV} \mathrm{FWHM,} \mathrm{Bohr}$ straggling, ideal beam and detector. No screening.

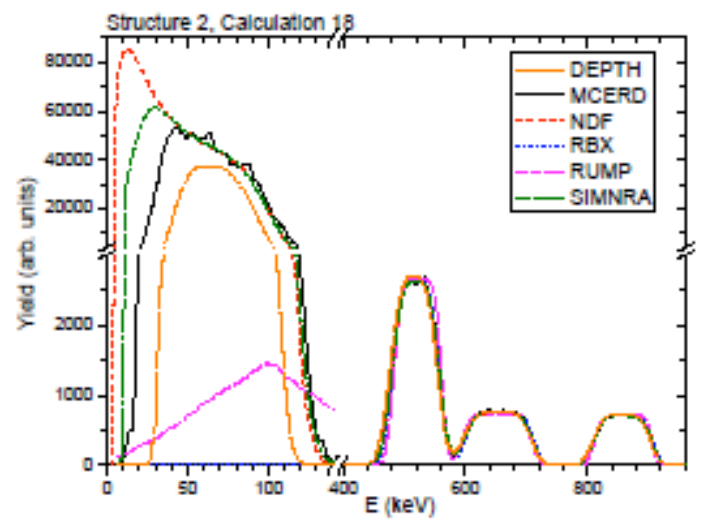

Figure 12. Calculation 18 - ${ }^{4} \mathrm{He}$ ERDA with Rutherford cross sections, from Si bulk / $\mathrm{CD}_{2} 150 \mathrm{~nm} / \mathrm{CH}_{2}$ $150 \mathrm{~nm} / \mathrm{CD}_{2} 150 \mathrm{~nm} .1 .8 \mathrm{MeV}{ }^{4} \mathrm{He}^{+}, \theta_{\text {scatt }}=30^{\circ}, \alpha_{\text {inc }}=15^{\circ}$, IBM geometry, $16 \mathrm{keV} \mathrm{FWHM,} \mathrm{Bohr}$ straggling, ideal beam and detector. No screening. Rutherford cross sections are used. 


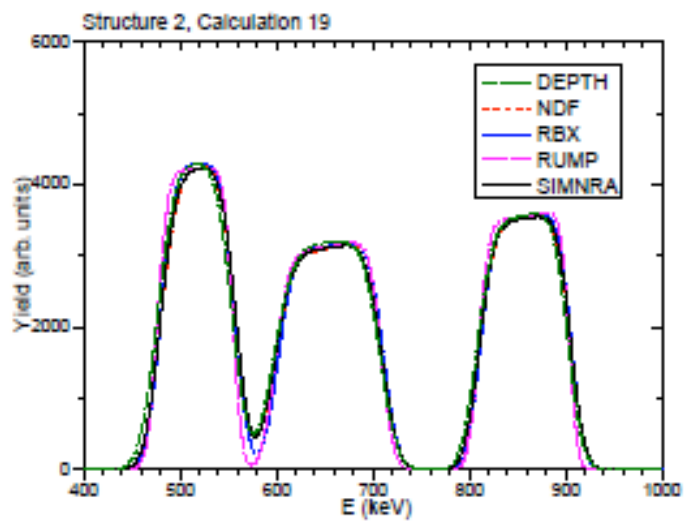

Figure 13. Calculation 19 - same as Calculation 18, but with given non-Rutherford cross sections.

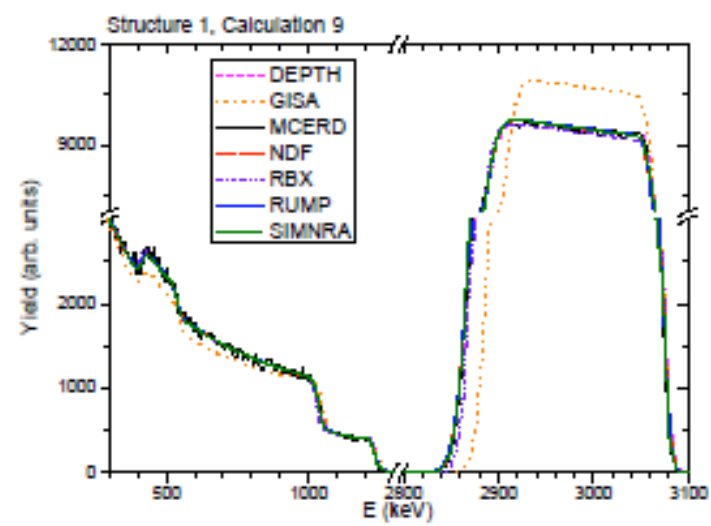

Figure 14. Calculation 9 - heavy ion RBS spectrum from $\mathrm{Si}$ bulk / $\mathrm{SiO}_{2} 200 \mathrm{~nm} / \mathrm{Au} 50 \mathrm{~nm} .3 .5 \mathrm{MeV}$ ${ }^{7} \mathrm{Li}^{+}, \theta_{\text {scatt }}=150^{\circ}, \alpha_{\text {inc }}=60^{\circ}$, IBM geometry, $16 \mathrm{keV} \mathrm{FWHM}$, Bohr straggling, ideal beam and detector. No screening. 


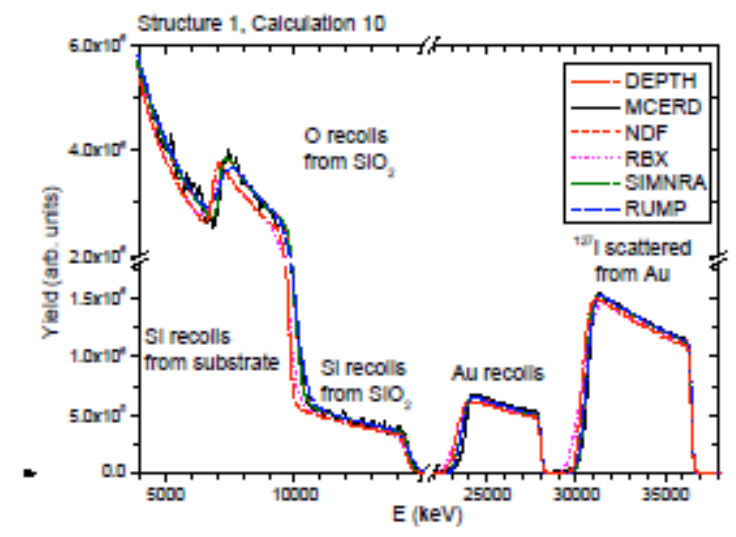

Figure 15. Calculation 10 - heavy ion ERDA spectrum from Si bulk / $\mathrm{SiO}_{2} 200 \mathrm{~nm} / \mathrm{Au} 50 \mathrm{~nm} .50 \mathrm{MeV}$ ${ }^{127} \mathrm{I}^{10+}, \theta_{\text {scatt }}=40^{\circ}, \alpha_{\text {inc }}=10^{\circ}$, IBM geometry, $200 \mathrm{keV} \mathrm{FWHM,} \mathrm{Bohr} \mathrm{straggling,} \mathrm{ideal} \mathrm{beam} \mathrm{and} \mathrm{detector.} \mathrm{No}$ screening.

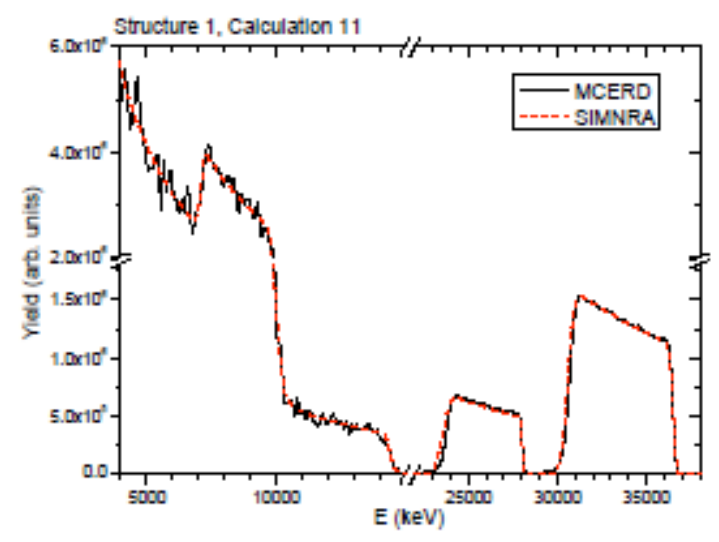

Figure 16. Calculation 11 - heavy ion ERDA, same as Calculation 10, but with a 300 ps time resolution for $50 \mathrm{~cm}$ time of flight, as opposed to a $200 \mathrm{keV}$ resolution. 


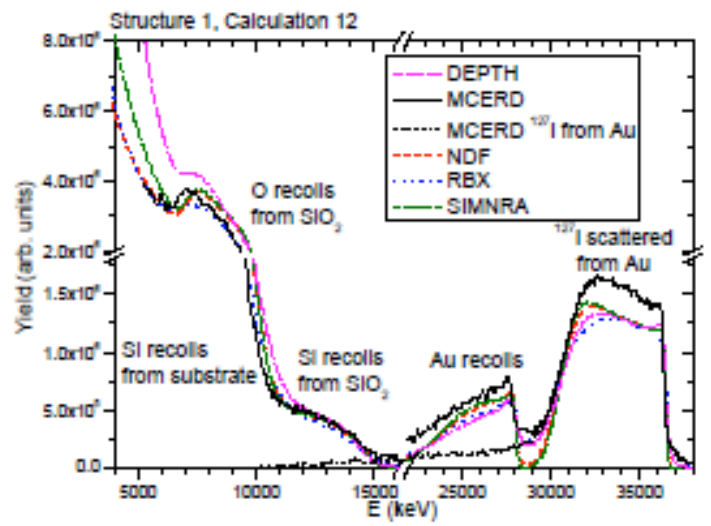

Figure 17. Calculation 12 - heavy ion ERDA, same as Calculation 10, but including mutliple scattering.

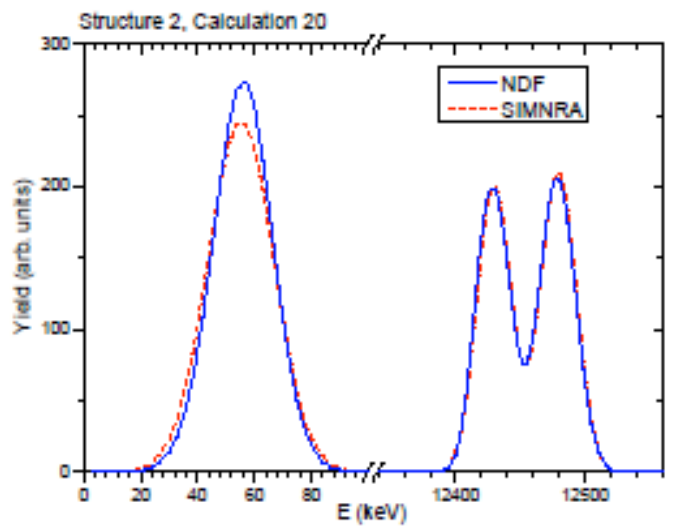

Figure 18. Calculation 20 - NRA spectrum from Si bulk / $\mathrm{CD}_{2} 150 \mathrm{~nm} / \mathrm{CH}_{2} 150 \mathrm{~nm} / \mathrm{CD}_{2} 150 \mathrm{~nm} .1$ $\mathrm{MeV}^{3} \mathrm{He}^{+}, \theta_{\text {scatt }}=170^{\circ}, \alpha_{\mathrm{inc}}=0^{\circ}, 16 \mathrm{keV} \mathrm{FWHM}$, Bohr straggling, ideal beam and detector. No screening. 


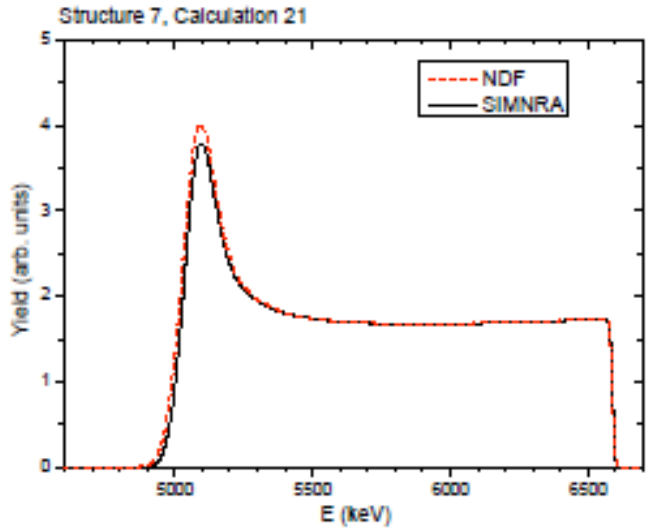

Figure 19. Calculation 21 - NRA spectrum from $\mathrm{N}_{1} \mathrm{Fe}_{4}$ bulk. $1 \mathrm{MeV}^{2} \mathrm{H}^{+}, \theta_{\text {scatt }}=170^{\circ}, \alpha_{\text {inc }}=0^{\circ}, 16 \mathrm{keV}$ FWHM, Bohr straggling, ideal beam and detector. No screening.

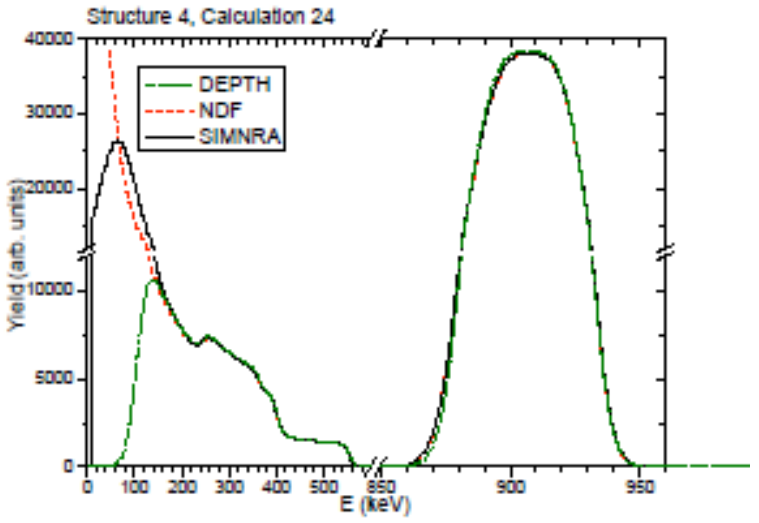

Figure 20. Calculation 24 - RBS spectrum with all broadening options, from Si bulk / $\mathrm{SiO}_{2} 200 \mathrm{~nm} / \mathrm{Au}$ $20 \mathrm{~nm} .1 .5 \mathrm{MeV}^{4} \mathrm{He}^{+}, \theta_{\text {scatt }}=150^{\circ}, \alpha_{\text {inc }}=60^{\circ}$, IBM geometry, $16 \mathrm{keV}$ FWHM, Bohr straggling with Chu correction, multiple scattering, realistic beam and detector. No screening. 


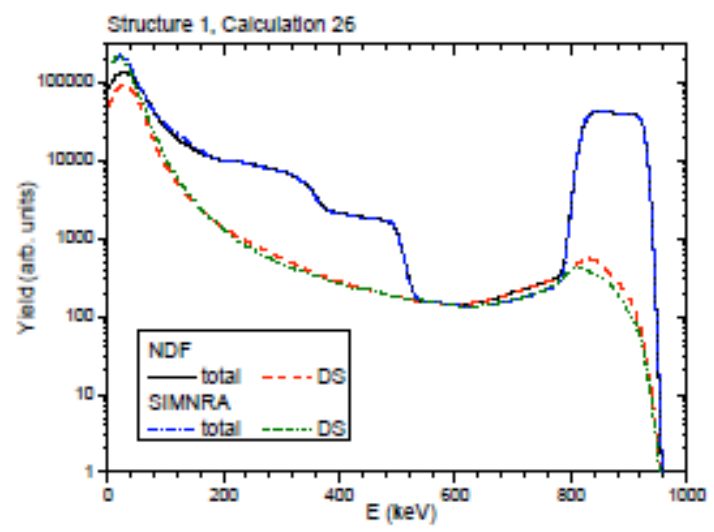

Figure 21. Calculation 26 - RBS spectrum, including the double scattering contribution (DS) from Si bulk / $\mathrm{SiO}_{2} 200 \mathrm{~nm} / \mathrm{Au} 50 \mathrm{~nm} .1 .5 \mathrm{MeV}^{4} \mathrm{He}^{+}, \theta_{\text {scatt }}=150^{\circ}, \alpha_{\mathrm{inc}}=60^{\circ}$, IBM geometry, $16 \mathrm{keV} \mathrm{FWHM,} \mathrm{Bohr}$ straggling, ideal beam and detector. No screening.

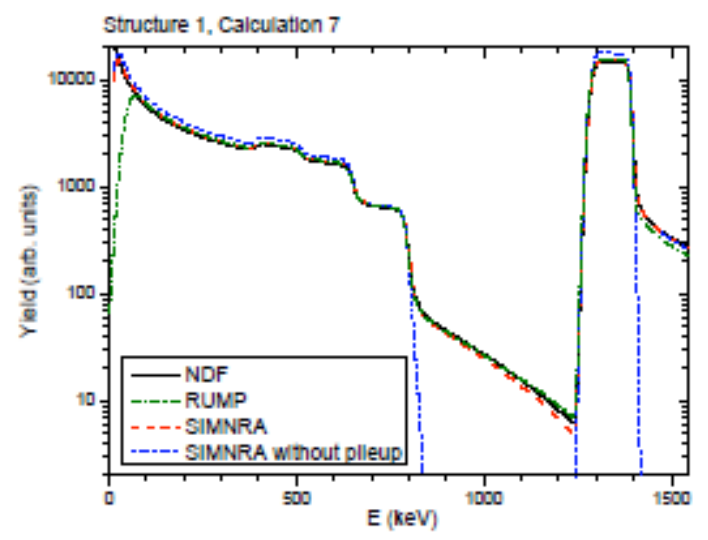

Figure 22. Calculation 7 - pulse pile-up calculation from $\mathrm{Si}$ bulk / $\mathrm{SiO}_{2} 200 \mathrm{~nm} / \mathrm{Au} 50 \mathrm{~nm}$. $1.5 \mathrm{MeV}$ ${ }^{4} \mathrm{He}^{+}, \theta_{\text {scatt }}=150^{\circ}, \alpha_{\text {inc }}=60^{\circ}$, IBM geometry, $16 \mathrm{keV} \mathrm{FWHM,} \mathrm{Bohr} \mathrm{straggling,} \mathrm{ideal} \mathrm{beam} \mathrm{and} \mathrm{detector.} \mathrm{No}$ screening. Pile-up included, $50 \mathrm{nA}, \mathrm{T}_{\mathrm{W}}=5 \mu \mathrm{s}$, no pile-up rejection system. 


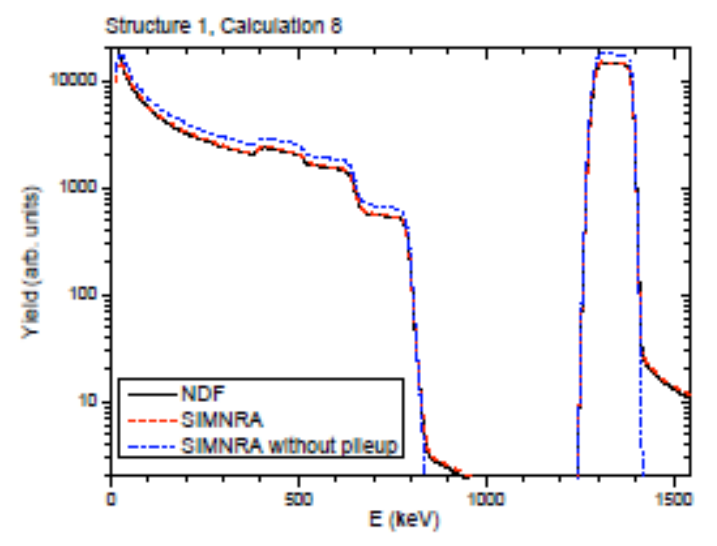

Figure 23. Calculation 8 - pulse pile-up calculation from $\mathrm{Si}$ bulk / $\mathrm{SiO}_{2} 200 \mathrm{~nm} / \mathrm{Au} 50 \mathrm{~nm}$. $1.5 \mathrm{MeV}$ ${ }^{4} \mathrm{He}^{+}, \theta_{\text {scatt }}=150^{\circ}, \alpha_{\text {inc }}=60^{\circ}$, IBM geometry, $16 \mathrm{keV} \mathrm{FWHM,} \mathrm{Bohr} \mathrm{straggling,} \mathrm{ideal} \mathrm{beam} \mathrm{and} \mathrm{detector.} \mathrm{No}$ screening. Pile-up included, $50 \mathrm{nA}, \mathrm{T}_{\mathrm{W}}=0.5 \mu$ s, pile-up rejection system with $0.5 \mu$ s resolution.

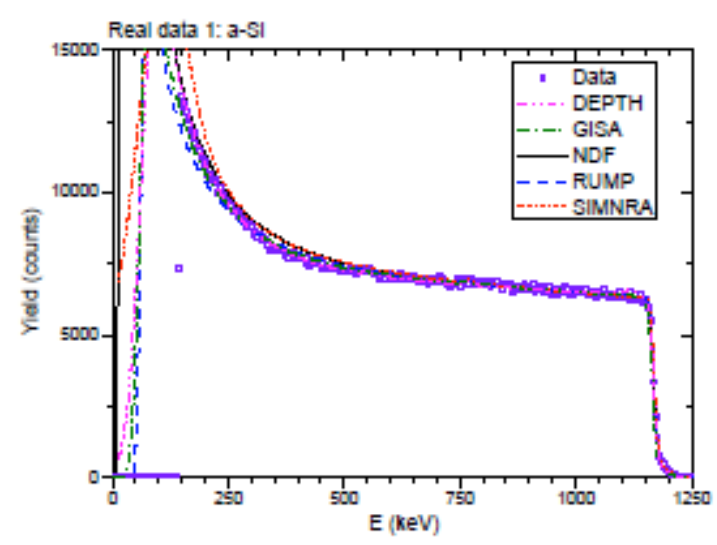

Figure 24. Experiment a-Si - $2 \mathrm{MeV}^{4} \mathrm{He} \mathrm{RBS}$ spectrum from amorphised Si. 


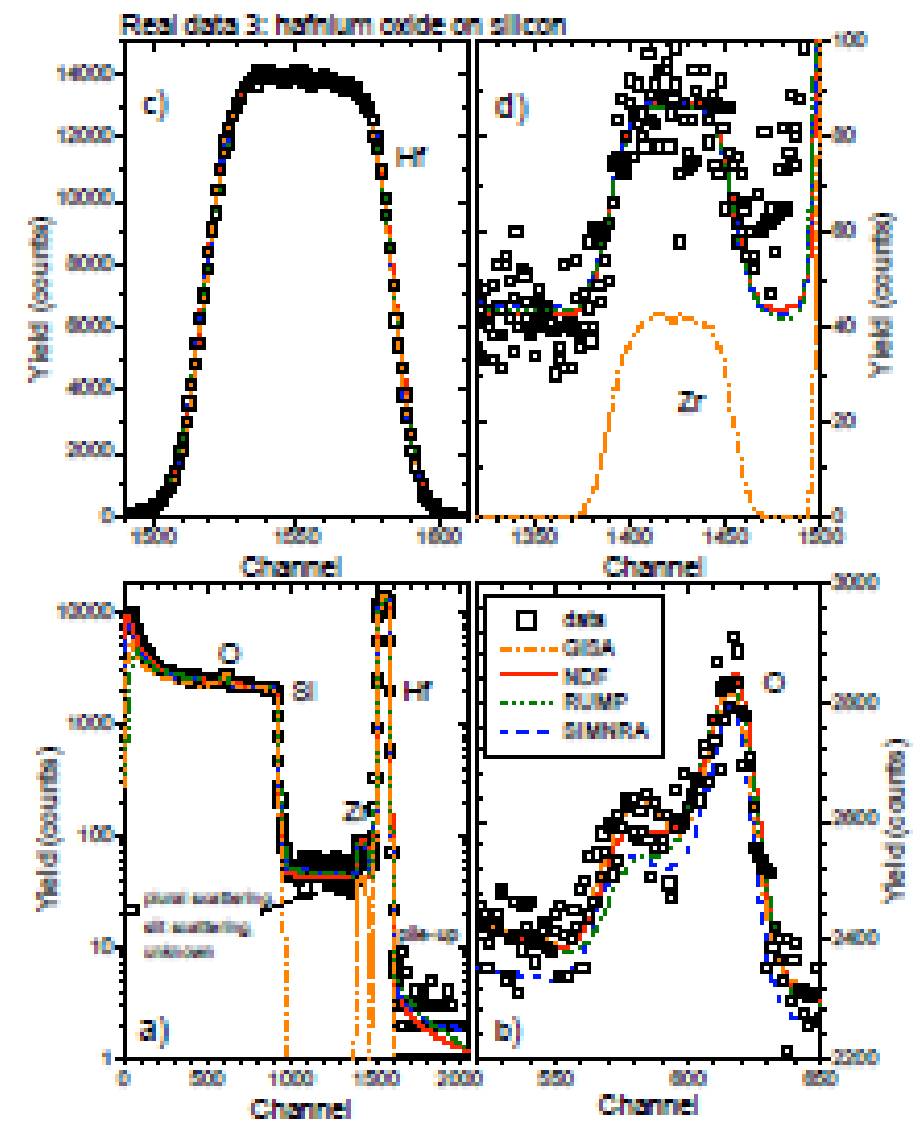

Figure 25. Experiment $\mathrm{HfO}-2.5 \mathrm{MeV}{ }^{4} \mathrm{He}$ RBS spectrum from a hafnium oxide film on silicon. a) The entire spectrum; b) O signal; c) Hf signal; d) $\mathrm{Zr}$ signal. 


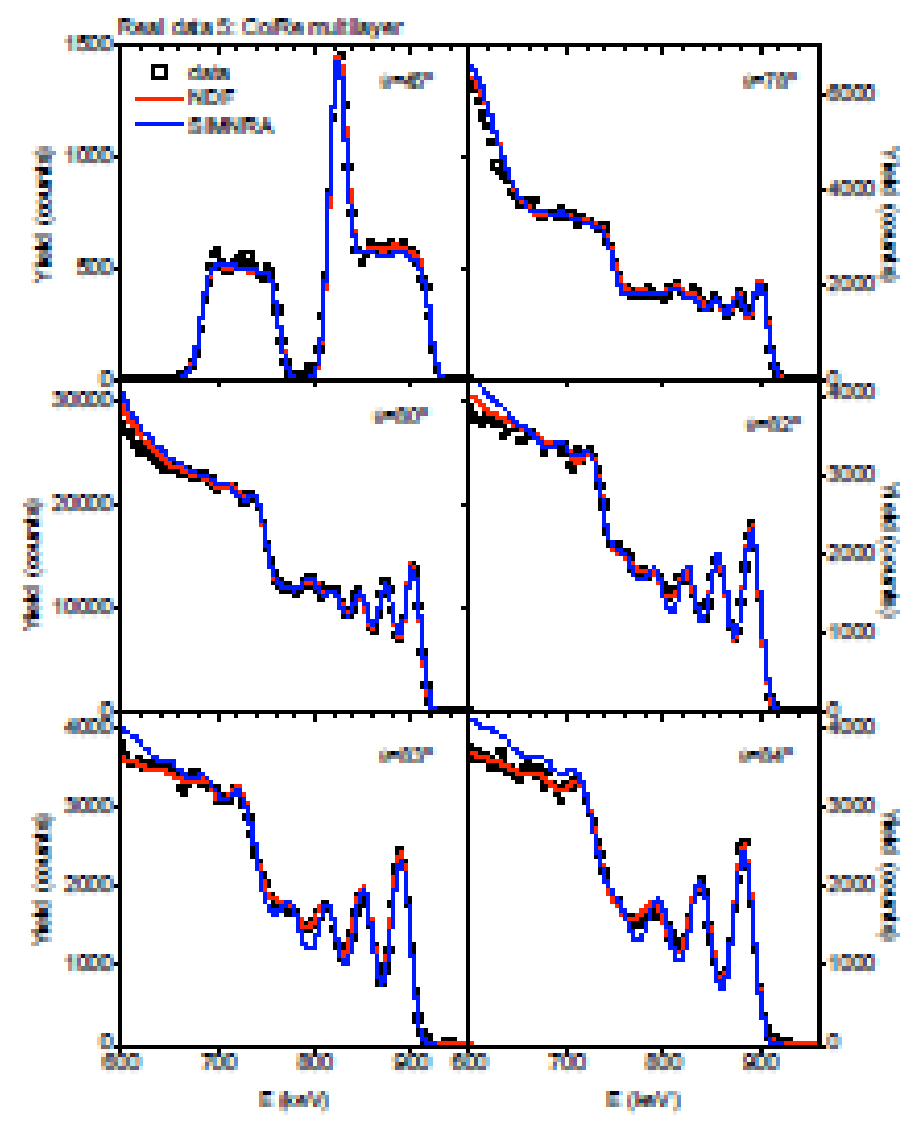

Figure 26. Experiment $\mathrm{Co} / \mathrm{Re}-1 \mathrm{MeV}^{4} \mathrm{He} \mathrm{RBS}$ spectra from a Si bulk / Re 5nm/(Co 2nm/Re $\left.0.5 \mathrm{~nm}\right)_{16}$ multilayer, taken at different angles of incidence in the Cornell geometry. 